\title{
PERK signaling through C/EBPS contributes to ER stress- induced expression of immunomodulatory and tumor promoting chemokines by cancer cells
}

\author{
Namratha Sheshadri (iD ${ }^{1,5,6 凶}$, Dipak K. Poria (iD) ${ }^{1,6}$, Shikha Sharan (iD ${ }^{1}$, Ying Hu (D) ${ }^{2}$, Chunhua Yan (D) ${ }^{2}$, Vishal N. Koparde ${ }^{3,4}$, \\ Kuppusamy Balamurugan (iD) ${ }^{1}$ and Esta Sterneck (iD) ${ }^{1 凶}$
}

This is a U.S. government work and not under copyright protection in the U.S.; foreign copyright protection may apply 2021

\begin{abstract}
Cancer cells experience endoplasmic reticulum (ER) stress due to activated oncogenes and conditions of nutrient deprivation and hypoxia. The ensuing unfolded protein response (UPR) is executed by ATF6, IRE1 and PERK pathways. Adaptation to mild ER stress promotes tumor cell survival and aggressiveness. Unmitigated ER stress, however, will result in cell death and is a potential avenue for cancer therapies. Because of this yin-yang nature of ER stress, it is imperative that we fully understand the mechanisms and dynamics of the UPR and its contribution to the complexity of tumor biology. The PERK pathway inhibits global protein synthesis while allowing translation of specific mRNAs, such as the ATF4 transcription factor. Using thapsigargin and tunicamycin to induce acute ER stress, we identified the transcription factor C/EBPS (CEBPD) as a mediator of PERK signaling to secretion of tumor promoting chemokines. In melanoma and breast cancer cell lines, PERK mediated early induction of C/EBP $\delta$ through ATF4independent pathways that involved at least in part Janus kinases and the STAT3 transcription factor. Transcriptional profiling revealed that C/EBPS contributed to $20 \%$ of thapsigargin response genes including chaperones, components of ER-associated degradation, and apoptosis inhibitors. In addition, C/EBP $\delta$ supported the expression of the chemokines CXCL8 (IL-8) and CCL20, which are known for their tumor promoting and immunosuppressive properties. With a paradigm of short-term exposure to thapsigargin, which was sufficient to trigger prolonged activation of the UPR in cancer cells, we found that conditioned media from such cells induced cytokine expression in myeloid cells. In addition, activation of the CXCL8 receptor CXCR1 during thapsigargin exposure supported subsequent sphere formation by cancer cells. Taken together, these investigations elucidated a novel mechanism of ER stress-induced transmissible signals in tumor cells that may be particularly relevant in the context of pharmacological interventions.
\end{abstract}

Cell Death and Disease (2021)12:1038; https://doi.org/10.1038/s41419-021-04318-y

\section{INTRODUCTION}

The endoplasmic reticulum (ER) is the primary site for synthesis, folding and post-translational processing of proteins. Cancer cells experience chronic ER stress due to intracellular activation of oncogenes and loss of tumor suppressors as well as microenvironmental stressors such as nutrient deprivation and hypoxia [1]. The ensuing unfolded protein response (UPR) is a cytoprotective mechanism to alleviate stress and restore cellular homeostasis [2]. The ER stress sensors ATF6, IRE1 and PERK trigger transcriptional reprogramming mediated by ATF6-N, XBP1S and ATF4, respectively, to effect the stress response pathways [3-5]. Cancer cells hijack these pathways to promote cell survival under stress and thereby facilitate tumor metastasis and therapy resistance [6, 7]. However, prolonged, unmitigated stress tips the balance toward apoptotic pathways [8]. Cancer cells that exhibit already elevated basal ER stress signaling can be hypersensitive to further ER stress, a concept that is being explored for cancer therapy [9]. For example, thapsigargin, the active component of the pro-drug mipsagargin, which is in clinical trials for advanced refractory cancers of the breast, brain, prostate and liver, is an inhibitor of the SERCA pump and causes ER stress through loss of calcium from the ER $[10,11]$.

Of the three UPR sensors, PERK inhibits global protein synthesis through phosphorylation of elF $2 a$, which in turn triggers the synthesis of specific proteins such as the ATF4 transcription factor. ATF4 mediates many adaptive responses but also induces the CCAAT/enhancer binding protein (C/EBP) homologous protein (CHOP, encoded by DDIT3), which can redirect the response

\footnotetext{
${ }^{1}$ Laboratory of Cell and Developmental Signaling, Center for Cancer Research, National Cancer Institute, 1050 Boyles Street, Frederick, MD, USA. ${ }^{2}$ Center for Biomedical Informatics and Information Technology, Center for Cancer Research, National Cancer Institute, 9609 Medical Center Dr., Rockville, MD, USA. ${ }^{3}$ CCR Collaborative Bioinformatics Resource (CCBR), Center for Cancer Research, National Cancer Institute, Bethesda, MD, USA. ${ }^{4}$ Advanced Biomedical Computational Science, Frederick National Laboratory for Cancer Research, Frederick, MD, USA. ${ }^{5}$ Present address: Susan Lehman Cullman Laboratory for Cancer Research, Ernest Mario School of Pharmacy, Rutgers, The State University of

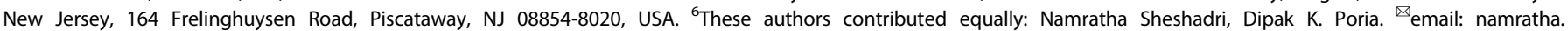
sheshadri@rutgers.edu; esta.sterneck@nih.gov

Edited by Professor Patrizia Agostinis
}

Received: 5 May 2021 Revised: 7 October 2021 Accepted: 13 October 2021

Published online: 01 November 2021 
toward cell death. PERK also collaborates with IRE1 to activate the NF-KB transcription factor, which mediates the expression of proinflammatory cytokines $[12,13]$. Thus, in addition to cancer cell intrinsic cell survival and death pathways, the ER stress-induced secretion of cytokines contributes to the transmission of ER stress and inflammation $[12,14]$. Given the Janus-faced nature of ER stress in the context of cancer, it is important to fully decipher the various UPR pathways and their contributions to tumor biology.

The transcription factor C/EBP $\delta$ (CEBPD) is a modular regulator of diverse cell signaling pathways that control cell proliferation, differentiation, survival or death, depending on cell type and context [15]. C/EBP $\delta$ expression is typically low, but induced in response to stimuli that include inflammation, hypoxia, and DNA damage [15], conditions that are known to induce ER stress. Accordingly, Cebpd-deficient mice are hypersensitive to high dose bacteremia and ionizing radiation $[16,17]$. In breast cancer cells, C/ EBP $\delta$ promotes stemness through amplification of hypoxia and IL6 signaling [18]. Here, we report that under acute ER stress C/EBP $\delta$ is induced by the PERK pathway to contribute to the induction of the chemokines CXCL8 and CCL20, thus revealing a novel mechanism for ER stress-mediated modulation of cancer cells' microenvironment.

\section{RESULTS \\ Endoplasmic reticulum stress induces C/EBPS expression in cancer cell lines}

To investigate C/EBP $\delta$ expression in response to ER stress, we first used thapsigargin, which induced C/EBPS protein levels along with the UPR effectors XBP1S and ATF4 in multiple cancer cell lines representing melanoma and breast cancer (Fig. 1a). Kinetic analysis in MDA-MB-435S melanoma cells [19], showed that C/EBPS induction peaked between $4-8 \mathrm{~h}$, relatively concurrent with XBP1S, ATF4 and CHOP (Fig. 1b). The ER chaperone BiP/GRP78 was induced after the first wave of response, as shown previously [20]. Similar data were obtained in KPL-4 (Fig. 1C) and four additional breast cancer cell lines (MDA-MB-468, BT-549, MCF-7, MDA-MB-231) albeit with varying kinetics and relationships to XBP1S, ATF4, and/or CHOP expression (Fig. S1a-d). In contrast, cells with high basal levels of C/EBPS [18, 21], such as the breast cancer cells SUM149 and SUM159, and mammary epithelial cell lines (MCF-10A and MCF-12A) rather reduced its expression in response to thapsigargin (Fig. S1e-h). To address C/EBP $\delta$ expression in response to other triggers of the UPR, we treated MDA-MB-435S cells with the N-glycosylation inhibitor tunicamycin, 2-deoxy-glucose, and anoxia [22, 23]. C/EBPS was induced under all conditions (Fig. 1d-f), and similar results were obtained with breast cancer cell lines (Fig. S1i-l). Analysis of mRNA levels in KPL-4 and/or MDA-MB-435S cells showed that not only the protein but also CEBPD mRNA was induced by thapsigargin (Fig. 1g, h) as well as tunicamycin, albeit with lower amplitude and shorter kinetics (Fig. 1i). Taken together, these data show that CEBPD is an early ER stress response gene in multiple cancer cells with low basal level expression.

\section{JAK/STAT3 activation by PERK contributes to CEBPD gene expression}

To identify which arm of the UPR was responsible for CEBPD mRNA induction, we individually silenced the three ER transmembrane sensors in MDA-MB-435S cells. Knockdown of ATF6 or IRE1a (ERN1) resulted in downregulation of the canonical targets HSPA5 (encoding $\mathrm{BiP}$ ) and $X B P 1 S$, respectively, but did not perturb CEBPD induction by thapsigargin (Fig. 2a, b). In contrast, depletion of PERK (EIF2AK3) not only impaired induction of its canonical target DDIT3 (CHOP) but also of CEBPD (Fig. 2c), which was confirmed at protein level (Fig. 2d). As alternative approach, the PERK kinase inhibitor GSK2606414 (GSK-414) [24] similarly reduced C/EBPS and ATF4 induction by thapsigargin at the protein and mRNA level (Fig. 2e, f), and likewise in KPL-4 cells (Fig. 2g, h). Depletion of
ATF4, a canonical mediator of PERK signaling, reduced induction of its target DDIT3 [25] but not of CEBPD (Fig. 2i). In contrast to pharmacological inhibitor studies in MDA-MB-231 cells [26], we did not observe changes in the basal levels of CEBPD when inhibiting the three principal UPR effectors by RNAi approaches. These data show that, in response to thapsigargin, CEBPD mRNA expression is induced by the PERK pathway through ATF4independent mechanisms.

To identify the mechanism of PERK induced CEBPD expression, we addressed the potential roles of other previously identified PERK substrates such as diacylglycerol (DAG), which activates PI3K-AKT-mTORC1 and RAS-RAF-MEK-ERK pathways, and the NRF2 transcription factor $[27,28]$. Pharmacological inhibition of MEK (U0126), mTORC1 (rapamycin) and AKT (MK-2206) or NRF2 silencing, respectively, did not reduce C/EBP $\delta$ induction by $\mathrm{Tg}$ (Fig. S2a-d), which ruled out these pathways.

In astrocytes, PERK activation of STAT3 through direct interaction with and activation of the janus kinase JAK1 has been described [29]. The CEBPD promoter can be targeted by the STAT3 transcription factor which is activated by IL-6 [15]. Indeed, IL-6mediated activation of STAT3 induced CEBPD expression also in MDA-MB-435S and KPL-4 cells (Fig. S2e, f). To address the potential role of a PERK-JAK-STAT3 pathway in CEBPD induction, we first monitored STAT3 activation in thapsigargin-treated MDAMB-435S cells by its Y705 phosphorylation status [30], which increased transiently preceding the induction of C/EBP $\delta$ and the canonical UPR effectors (Figs. 3a and S2g). Inhibition of PERK by siRNA or GSK-414 attenuated C/EBPS protein induction and STAT3 phosphorylation (Figs. 3b, $\mathrm{c}$ and $\mathrm{S} 2 \mathrm{~h}, \mathrm{i}$ ), while inhibition of the other pathways did not (Fig. S2g-i). Next, we used siRNA to deplete STAT3, which had no effect on thapsigargin-induced ATF4 expression but reduced C/EBP $\delta$ induction at the RNA and protein levels (Fig. 3d, e). As alternative approach, we used pharmacological inhibition of STAT3 by STATTIC [31], which completely abrogated CEBPD mRNA and protein induction (Fig. 3f, g). However, ATF4 induction was also attenuated, most likely due to STATTIC's broad off-target effects [32]. Next, we assessed the role of JAKs with three inhibitors [33], all of which efficiently attenuated STAT3 phosphorylation and C/EBP $\delta$ mRNA and protein induction but did not significantly perturb induction of XBP1 and ATF4 protein (Fig. 3h, i). In KPL-4 cells, JAK inhibition also attenuated C/EBPS mRNA and protein accumulation (Fig. 3j, k). Lastly, we asked whether glucose deprivation (GD) as a nonpharmacological trigger of ER stress, also activated this pathway. C/EBP $\delta$ protein expression, along with ATF4, was induced, but only after $8-24 \mathrm{~h}$ of GD while STAT3 phosphorylation was inhibited, and was not affected by GSK-414 (Fig. S2j, k). In contrast to its protein, CEBPD mRNA expression was downregulated (Fig. S2I). Thus, engagement of the JAK/STAT pathway by PERK may depend on the context and/or severity of ER stress, which is known to modulate the type of UPR [34]. Taken together, these results show that thapsigargin induces CEBPD expression through PERK and JAK kinases and in part by the STAT3 transcription factor.

\section{C/EBPS regulates a subset of ER stress induced genes}

To determine the transcriptional program regulated by C/EBP $\delta$ during ER stress, we conducted an mRNA-Seq analysis. MDA-MB$435 \mathrm{~S}$ cells were transfected with two independent CEBPD siRNAs or two independent controls followed by treatment with thapsigargin for $6 \mathrm{~h}$. Among genes that were either induced or repressed by thapsigargin, 299 (20\%) were significantly affected by CEBPD silencing (Fig. 4a, b). Because a reliable antibody for C/EBP $\delta$ ChIP-Seq was not available at the time, we mined prior ChIP datasets for binding to these genes' promoters by any of the five C/EBP family proteins (C/EBPa, C/EBP $\beta, C / E B P \gamma, C / E B P \delta$, and $C / E B P \varepsilon)$ that share a common binding motif, which indicated the potential for C/EBP $\delta$ binding within the proximal 


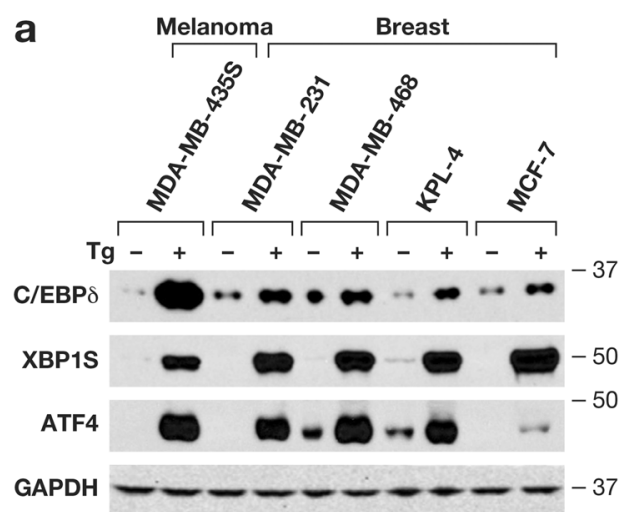

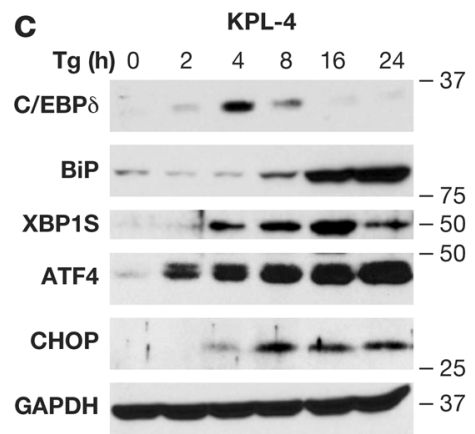

d

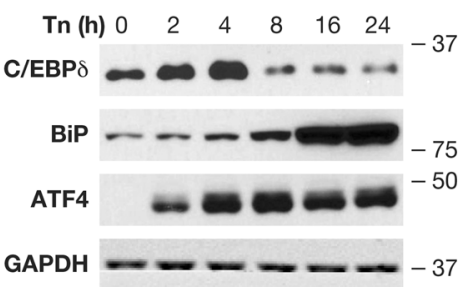

b

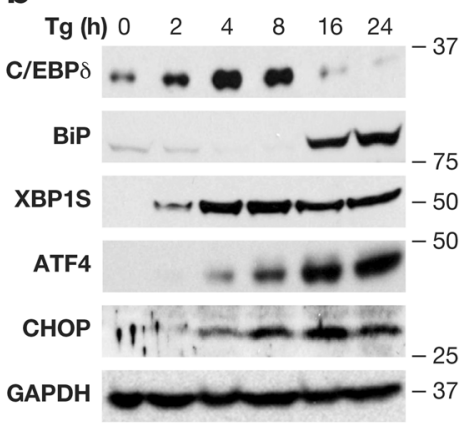

e

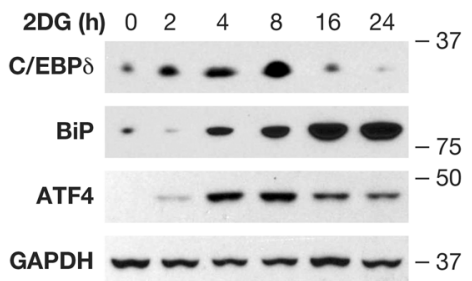

f

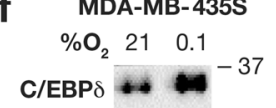

KPL-4

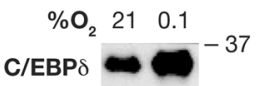

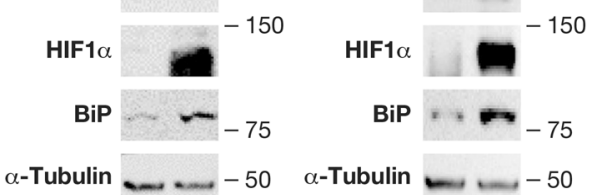

g

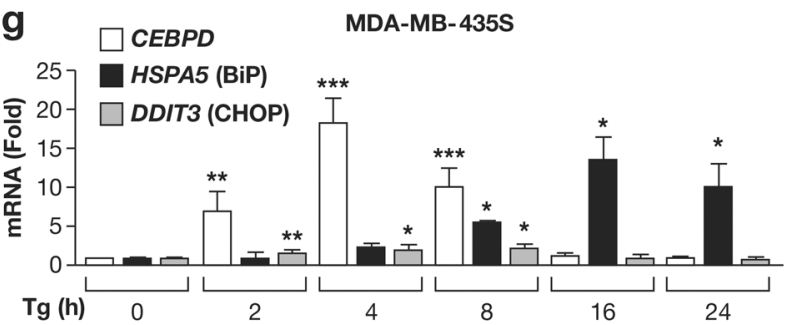

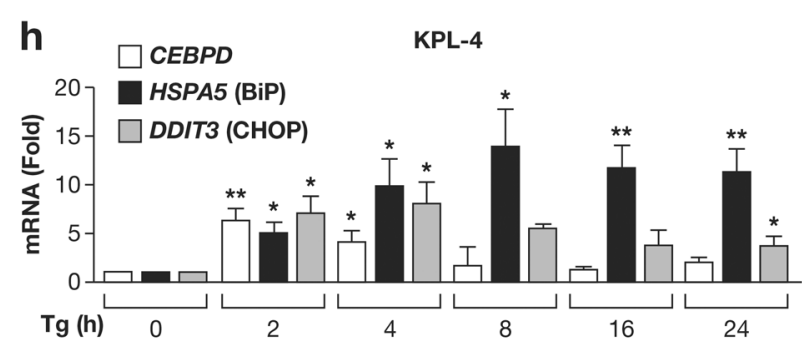

i

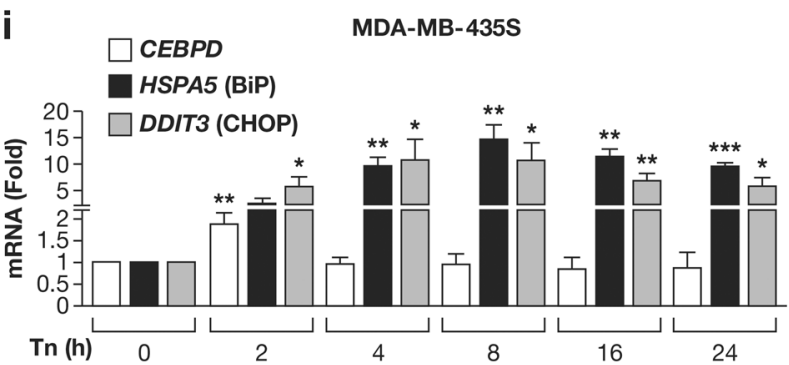

Fig. 1 Endoplasmic reticulum stress modulates C/EBPS expression in multiple cell lines. a Western blot analysis of the indicated proteins from cell lines representing melanoma and breast cancer treated with $100 \mathrm{nM}$ of Thapsigargin $(\mathrm{Tg})$ for $4 \mathrm{~h}$. $\mathbf{b}-\mathbf{e}$ Western blot analysis of $\mathbf{b}$ MDA-MB-435S or c KPL-4 cells treated with $100 \mathrm{nM} \mathrm{Tg}$ for the indicated times, d MDA-MB-435S cells treated with $10 \mu \mathrm{g} / \mathrm{ml}$ Tunicamycin (Tn) or e $10 \mathrm{mM}$ 2-deoxy-glucose (2DG) for the indicated duration $(0 \mathrm{~h}=$ vehicle treated for $24 \mathrm{~h}) . \mathrm{f} \mathrm{MDA-MB}-435 \mathrm{~S}$ and KPL-4 cells exposed to anoxia $\left(0.1 \% \mathrm{O}_{2}\right)$ or ambient $\left(21 \% \mathrm{O}_{2}\right)$ for $24 \mathrm{~h}$. a-f labels on the right indicate molecular weight in $\mathrm{kDa}$ for this and subsequent Figures. $\mathbf{g}$, $\mathbf{h}$ qRT-PCR analysis of mRNA levels as indicated in $\mathbf{g}$ MDA-MB-435S and $\mathbf{h}$ KPL-4 cells treated as in $\mathbf{b}$. $\mathbf{i}$ qRT-PCR analysis of mRNA levels in MDA-MB-435S cells treated with $10 \mu \mathrm{g} / \mathrm{ml} \mathrm{Tn}$ for the indicated times. Data are represented as mean \pm S.E.M, $n=3,{ }^{*} P<0.05,{ }^{* *} P<0.01,{ }^{* * *} P<0.001$.

gene promotors of 247 genes (Table S1). Ingenuity Pathway Analysis (QIAGEN Inc.) [35] revealed that the top Canonical Pathway represented by the differentially expressed genes (DEGs) was the "unfolded protein response" $(P=2.13 \mathrm{E}-09)$. "Cell death and survival" was the top altered Molecular and Cellular Function $(P=1.03 \mathrm{E}-18)$. PERK was among the most affected upstream regulators (EIF2AK3, $P=6.61 \mathrm{E}-13$; Table S2), suggesting that C/EBP $\delta$ is one of the mediators of PERK signaling. For validation by qRT-PCR analysis of independent mRNA samples, we selected several of the Tg-induced/CEBPD-activated DEG's relevant to ER homeostasis (Fig. 4c) and confirmed differential expression of genes that function in Endoplasmic Reticulum Associated Degradation (ERAD) such as DNAJB9 and EDEM1, the stress-response transcriptional regulator of lipid homeostasis (SREBF1), and the BIRC3 gene encoding cellular inhibitor of apoptosis protein 2 (c-IAP2). Among secreted factors, CXCL8 (encoding IL-8) and CCL20 showed the highest fold-change due to SiCEBPD and were validated along with IL21R and IRF1 (Fig. 4C) as inflammatory signaling molecules. Similar results were obtained in the KPL-4 breast cancer cell line (Fig. 4d). Taken together, these data show that C/EBPS, directly and/or indirectly mediates the expression of many genes in response to thapsigargin. 
a

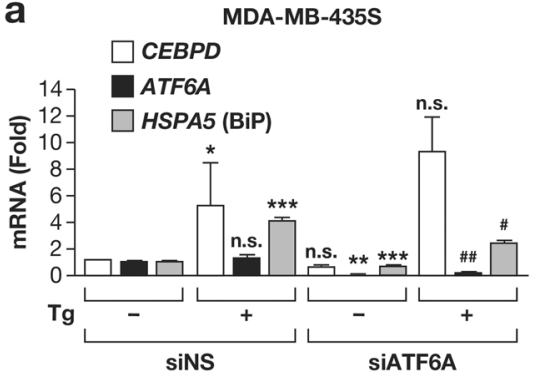

b

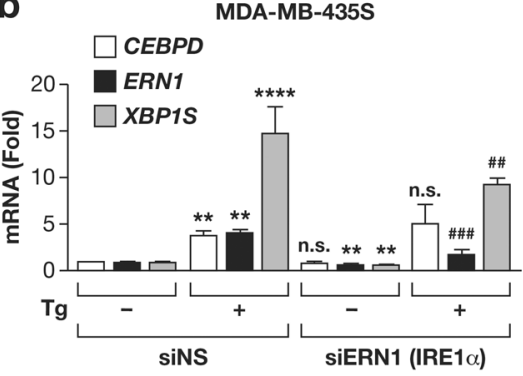

C MDA-MB-435S

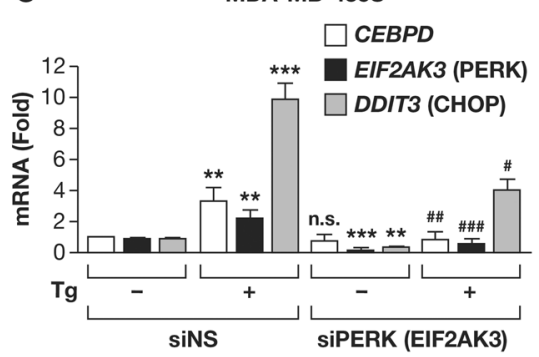

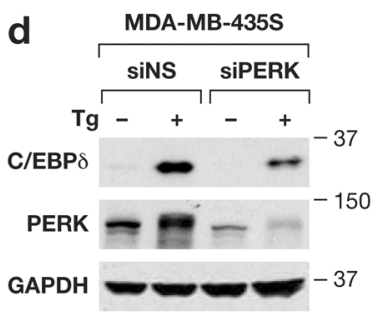

h

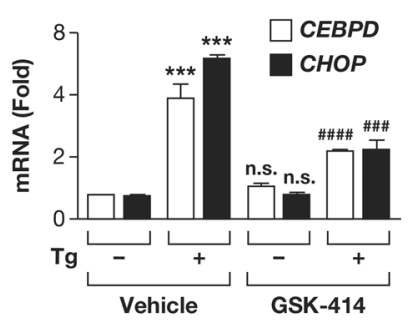

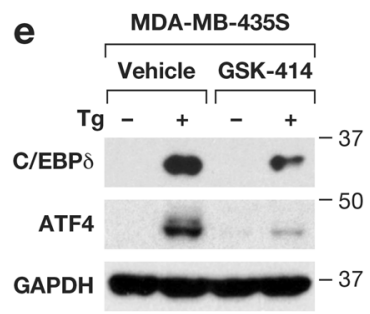

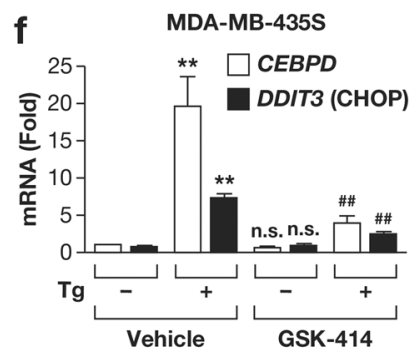

g

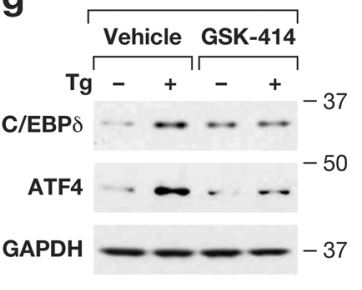

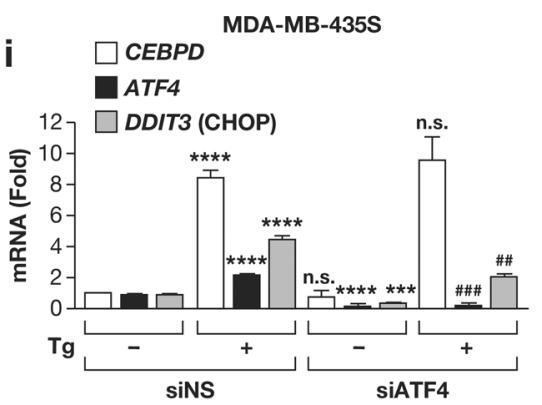

Fig. 2 C/EBPS is induced by the PERK pathway of the unfolded protein response in MDA-MB-435S and KPL-4 cells. a-C qRT-PCR analysis of the indicated mRNA levels in MDA-MB-435S cells transfected with control siRNA (siNS) or a siATF6A (ATF6 $\alpha$ ), b siERN1 (IRE1 $\alpha$ ), or c siPERK (targeting EIF2AK3), and treated for $6 \mathrm{~h}$ with $100 \mathrm{nM} \mathrm{Tg}(+)$ or DMSO (-). d Western blot analysis of MDA-MB-435S cells transfected with siRNA and treated with $\mathrm{Tg}(100 \mathrm{nM})$ for $3 \mathrm{~h}$ as indicated. $\mathbf{e}-\mathbf{h}$ Western blot analysis (e, $\mathbf{g})$ and qRT-PCR analysis (f, h) of MDA-MB-435S (e, f) and KPL-4 $(\mathbf{g}, \mathbf{h})$ cells treated with DMSO or Tg $(100 \mathrm{nM})$ for $3 \mathrm{~h}$ and with or without pre-treatment with $1 \mu \mathrm{MM}$ GSK2606414 (GSK-414). i qRT-PCR analysis of the indicated mRNA levels in MDA-MB-435S cells transfected with siNS or siATF4 and treated with DMSO or Tg for $6 \mathrm{~h}$. Quantitative data are represented as mean \pm S.E.M $n=3 ;{ }^{*} P<0.05,{ }^{* *} P<0.01,{ }^{* * *} P<0.001,{ }^{* * *} P<0.0001$ for comparisons to siNS or vehicle control ${ }^{*}$ without Tg or \#with Tg treatment, n.s., not significant.

\section{C/EBP $\delta$ induces CXCL8 and CCL20 transcription}

Although CEBPD knockdown attenuated induction of pro-survival genes such as $B I R C 3$, our pilot experiments did not suggest that C/EBPS played a significant role in cell survival upon thapsigargin treatment. Thus, we focused our attention on the expression of the chemokines CXCL8 and CCL20. Inhibition of PERK in CEBPD-silenced cells further reduced the induction of CXCL8 and CCL20 mRNA expression by thapsigargin but did not completely inhibit their induction (Fig. 5a). These data indicate that CXCL8 and CCL20 are induced by C/EBPS in cooperation with other PERK-activated factors $[36,37]$ as well as PERK-independent pathways. To further evaluate the role of C/EBP $\delta$ in the regulation of CXCL8 and CCL20, we overexpressed C/EBPS in MDA-MB-435S and HEK293T cells, which was sufficient to upregulate the endogenous mRNA levels of these chemokines, while a mutant without transactivation domain had no effect (Fig. 5b, c). C/EBP $\delta$ binding to the CCL20 promoter has been reported [38]. C/EBPS ChIP-Seq data from HepG2 cells indicated binding to a site in the proximal promoter of CXCL8 (Fig. $5 \mathrm{~d}$ ). Transactivation of a CXCL8 promoter reporter construct by C/EBP $\delta$ was significantly dependent on the presence of this region (Fig. $5 \mathrm{e}$, f). These data show that C/EBP $\delta$ could induce gene expression in the absence of ER stress signals. To interrogate cells with high basal level of C/EBPS, we silenced it in SUM149 and SUM159 cells and observed reduction in CXCL8 in both lines and CCL2O in SUM149 (Fig. 5g).
Next, we analyzed xenograft tumors of SUM159 cells with doxycycline-inducible shRNA expression [18]. Tumors from doxycycline-treated control mice exhibited increased CXCL8 expression, which may be due to increased ER stress [39] (Fig. 5h). However, when CEBPD was concomitantly silenced, CXCL8 expression was reduced as well (Fig. 5h). CCL20 expression was more variable and differences between groups not statistically significant. Taken together, these data show that C/EBP $\delta$ promotes expression of CCL20 and/or CXCL8 expression, most likely through direct binding to their endogenous promoters.

\section{Transient exposure to thapsigargin triggers secretion of CXCL8 and CCL20, paracrine modulation of immune cells, and cancer cell growth}

The chemokines CXCL8 and CCL20 are modulators of immune cells as well as cancer cells [40,41]. To assess the effect of ER stress-induced secreted factors, we treated cells with thapsigargin for $30 \mathrm{~min}$ followed by removal of the drug as described [42] and collection of conditioned media (CM). First, we confirmed that $30 \mathrm{~min}$ of thapsigargin exposure were sufficient to trigger lasting UPR pathway activation [43] in MDA-MB-435S and KPL-4 cells, indicated by increased expression of XBP1S, ATF4, CHOP, and C/ EBP $\delta$ and STAT3 phosphorylation (Figs. $6 a, b$ and S3). The mRNAs of CXCL8 and CCL20 were highly induced in both cell lines albeit 

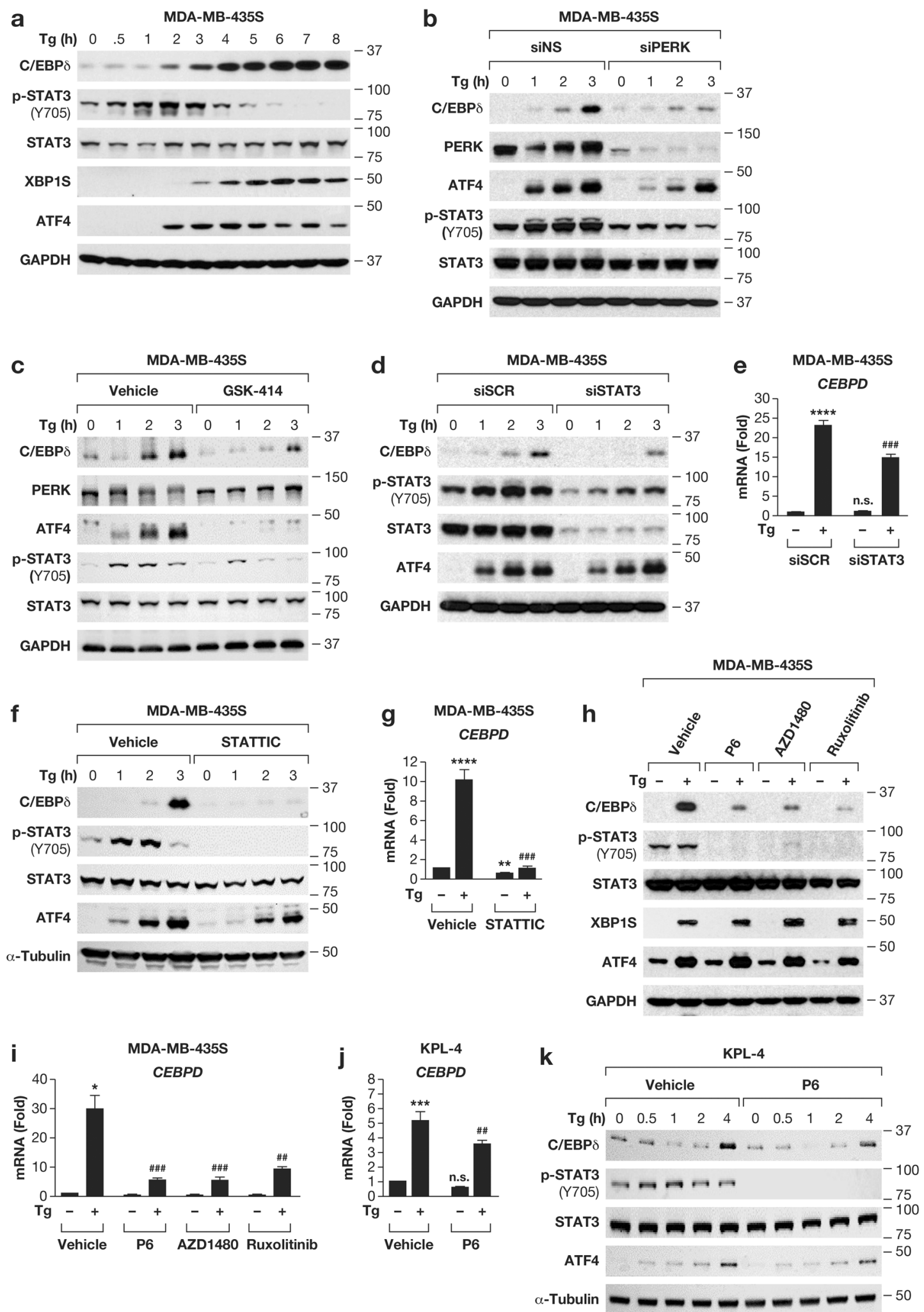

with different kinetics (Fig. 6c, d). CXCL8 protein accumulated steadily in media from pulse-treated MDA-MB-435S cells, while CCL20 protein was only detectable after $24 \mathrm{~h}$ at low concentration (Fig. 6e, f). Prolonged activation of the UPR by short-term treatment is likely due to thapsigargin's mechanism of irreversible inhibition of the SERCA protein [44].
Next, we incubated the human HL-60 promyelocytic cell line with CM from MDA-MB-435S cells that had been pulse-treated with thapsigargin (postTg-CM). First, we determined that postTgCM treatment did not lead to measurable UPR activation in HL-60 cells, as the mRNA levels of HSPA5, XBP1S and DDIT3 were not induced but did increase in response to thapsigargin (Fig. S4a, b). 
Fig. 3 PERK-dependent JAK/STAT3 activation contributes to C/EBPS induction. a Western blot analysis of the indicated proteins in MDAMB-435S cells treated with $100 \mathrm{nM}$ Tg for the indicated times $(0 \mathrm{~h}=$ vehicle treated for $8 \mathrm{~h})$. $\mathbf{b}$, c Western blot analysis of MDA-MB-435S cells (b) transfected with siNS or siPERK, or c pre-treated with $1 \mu \mathrm{M}$ GSK-414, and treated with $\mathrm{Tg}$ for the indicated times $(0 \mathrm{~h}=\mathrm{vehicle}$ treated for $3 \mathrm{~h}$ ). d Western analysis of cells treated as in b after transfection with siSCR or siSTAT3. e qRT-PCR analysis of CEBPD mRNA in cells as in d treated for $3 \mathrm{~h}$ with Tg. $\mathbf{f}$ Western analysis of MDA-MB-435S cells as in c pre-treated with DMSO or STAT3 inhibitor STATTIC (20 $\mu$ M). $\mathbf{g}$ qRT-PCR analysis of CEBPD mRNA in cells as in $\mathbf{f}$ treated for $3 \mathbf{h}$ with Tg. $\mathbf{h}$, $\mathbf{i}$ Western (h) and qRT-PCR (i) analysis of MDA-MB-435S cells treated with DMSO or Tg $(100 \mathrm{nM})$ for $3 \mathrm{~h}$ and pre-treated with the JAK inhibitors Pyridone6 (P6, $1 \mu \mathrm{M})$, AZD1480 (1 $\mu \mathrm{M})$ or Ruxolitinib $(1 \mu \mathrm{M})$ as indicated. $\mathbf{j}$, k qRT-PCR (j) and Western blot analysis (k) of KPL-4 cells treated with DMSO or Tg $(100 \mathrm{nM})$ for $3 \mathrm{~h}(\mathbf{j})$ or as indicated (k) with or without pretreatment with JAK inhibitor Pyridone6 (P6, $1 \mu \mathrm{M})$. Quantitative data are represented as mean \pm S.E.M, $n=3$; ${ }^{*} P<0.05$, ${ }^{* *} P<0.01$, ${ }^{* * *} P<0.001$, ${ }^{* * * *} P<0.0001$ for comparisons to control siRNA or vehicle *without or \#with Tg-treatment, n.s., not significant.

Next, we tested whether postTg-CM modulated inflammatory gene expression. Several genes encoding cytokines (IL12, IL6, TNFA) and the IL-1 receptor antagonist ILIRA were induced by postTg-CM, whereas expression of $I L 10$ was inhibited (Fig. $6 \mathrm{~g}$ ). Addition of SX-682, an inhibitor of the CXCL8 receptors CXCR1 and CXCR2 [45], blocked these responses (Fig. 6g). Similar results were obtained with postTg-CM from KPL-4 cells (Fig. S4c). We used SX682 instead of antibody-mediated neutralization of CXCL8 because HL-60 cells express Fc receptors, which would trigger inflammatory gene expression [46, 47]. Therefore, we cannot rule out the potential role of other CXCR1/2 ligands [48]. However, the mRNA-Seq data did not indicate that any of them were induced by Tg. Nevertheless, two different PERK inhibitors or silencing of CEBPD in MDA-MB-435S cells significantly reduced the paracrine activity of post-TgCM on HL-60 gene expression (Fig. 6h, i). Taken together, our data demonstrate that PERK-C/EBPS-dependent factors secreted from cancer cells after exposure to thapsigargin modulate myeloid cell gene expression through activation of CXCR1/2 receptors.

In breast cancer, CXCL8 promotes cancer cell stemness [49], which increases cells' ability to grow as spheres in suspension culture (3D) [50]. To test the effect of UPR in this paradigm, KPL-4 cells were treated for $6 \mathrm{~h}$ with thapsigargin and/or GSK-414 or SX682 , followed by seeding in suspension without drugs. We found that KPL-4 cells proliferated robustly under these conditions, barring conclusions about selection of stem cells. However, both $\mathrm{Tg}+\mathrm{GSK}-414$ and $\mathrm{Tg}+\mathrm{SX}-682$ pre-treatments significantly reduced the number of live cells recovered after $4 \mathrm{~d}$, while exposure to single agents had no effect (Fig. 6j, k). While CXCR2 transcripts were not detectable in KPL-4 cells under any of these conditions, CXCR1 transcript levels were low in 2D, modestly induced in 3D and more so in thapsigargin-treated cells (Fig. S5a). GSK-414, but not SX-682, completely abolished CXCR1 induction (Fig. S5a). CEBPD-depletion showed that C/EBP $\delta$ also contributed to CXCR1 expression in KPL-4 cells (Fig. S5b). Lastly, in this paradigm, antibody-mediated neutralization of CXCL8 during Tg-exposure reduced the number of live cells after 3D culture (Fig. 6I). Taken together, these data show that PERK and CXCR1 signaling poise thapsigargin-treated cells for survival and/or growth in suspension, which is mediated in part by CXCL8.

\section{PERK-C/EBPS signaling leads to sustained CXCL8 and CCL20 expression}

Earlier, we showed that under chronic ER stress, PERK signaling induced PSTAT3 and C/EBPS, which mediated CXCL8 and CCL2O induction. Therefore, we assessed whether this pathway also contributed to these chemokines' expression after transient thapsigargin treatment. As seen with chronic treatment, PERK inhibition by GSK-157 during pulse treatment diminished STAT3 phosphorylation, C/EBPS and ATF4 protein expression (Fig. 7a) and the induction of CEBPD, CXCL8 and CCL20 mRNA (Fig. 7b) in MDA-MB-435S cells. Similar results were obtained with GSK-414 or PERK siRNA (Fig. S6a-d). Accordingly, PERK-silencing and both PERK inhibitors reduced the accumulation of CCL20 and/or CXCL8 in $\mathrm{CM}$ assessed at $6 \mathrm{~h}$ (Fig. S6e-g) and $24 \mathrm{~h}$ after pulse treatment (Fig. 7c, d). Similar results were obtained with KPL-4 cells
(Fig. 7e-g). Lastly, silencing of CEBPD in MDA-MB-435S and KPL4 cells also reduced the amounts of secreted CXCL8 and CCL20 (Fig. 7h, i). Taken together, these data confirm that the PERKC/EBPS pathway significantly contributes to chemokine expression after transient exposure to thapsigargin.

\section{DISCUSSION}

Autocrine and paracrine signaling by the tumor cell secretome are critical determinants of tumor biology by modulating the microenvironment and tumor cell phenotypes that contribute to tumor development and therapeutic outcomes. In this report, we describe a signaling pathway from PERK through C/EBP $\delta$ in cancer cells, which contributes to expression and secretion of CXCL8/IL-8 and CCL20 (Fig. 8), two chemokines that have well-documented tumor promoting effects through direct action on cancer cells as well as various immune cells $[40,48]$. Activation of the STAT3 pathway may occur through direct interaction of PERK with JAK [29] or indirect mechanisms. In the context of immune cells, it is well established that the UPR triggers proinflammatory signaling $[12,51]$, including PERK-mediated induction of cytokine genes [29]. In cancer cells, IRE1 is reported to promote immunomodulatory cytokine expression [13] including CXCL8 [52]. PERK has been shown to induce CXCL8 through NF-KB and ATF4 $[36,37]$. Our study adds C/EBP $\delta$ to the arsenal of UPR mediators. In addition, we find that PERK-C/EBP $\delta$ can induce both CXCL8 and CXCR1, thus issuing two-pronged activation of this pathway. Specifically, we show that cancer cells that had been exposed to thapsigargin, utilize this pathway for survival and growth in suspension.

C/EBP $\delta$ functions as a proximal ER stress responsive transcription factor that is transcriptionally induced at least in part through the JAK/STAT3 pathway. Studies in astrocytes revealed PERKmediated activation of JAK-STAT3 signaling and induction of cytokines including CCL20 as a potential mechanism underlying neurological diseases [53]. Given that C/EBP $\delta$ can be expressed in astrocytes [54], we speculate that C/EBP $\delta$ may mediate some of PERK's functions in these conditions. Here, we show that the PERKJAK/STAT3 pathway can operate in certain cancer cell lines, adding to the molecular repertoire of ER stress-induced intra- and intercellular responses. The varying kinetics of C/EBPS expression in different cancer cell lines may depend on the intrinsic variations of base line activation of the UPR and other pathways and/or balance of different arms of the UPR. For example, NF-KB is a candidate pathway that may also participate in ER stress-induced CEBPD transcription $[15,55]$. On the other hand, the IRE1 pathway can inhibit C/EBP $\delta$ as seen by IRE1 deletion in mouse hepatocytes [56]. Thus, it may be interesting to assess if IRE1 is responsible for the transient nature of C/EBP $\delta$ induction in cancer cells experiencing ER stress, and/or for the reduction of C/EBPS levels in cell lines with high basal expression.

Our transcriptomic study showed that C/EBPS contributed to the regulation of about $20 \%$ of the thapsigargin-modulated transcriptome in MDA-MB-435S cells. The spectrum of direct and indirect C/EBP $\delta$ targets will certainly depend on the trigger for ER stress and cell type. In addition, it remains to be determined to 

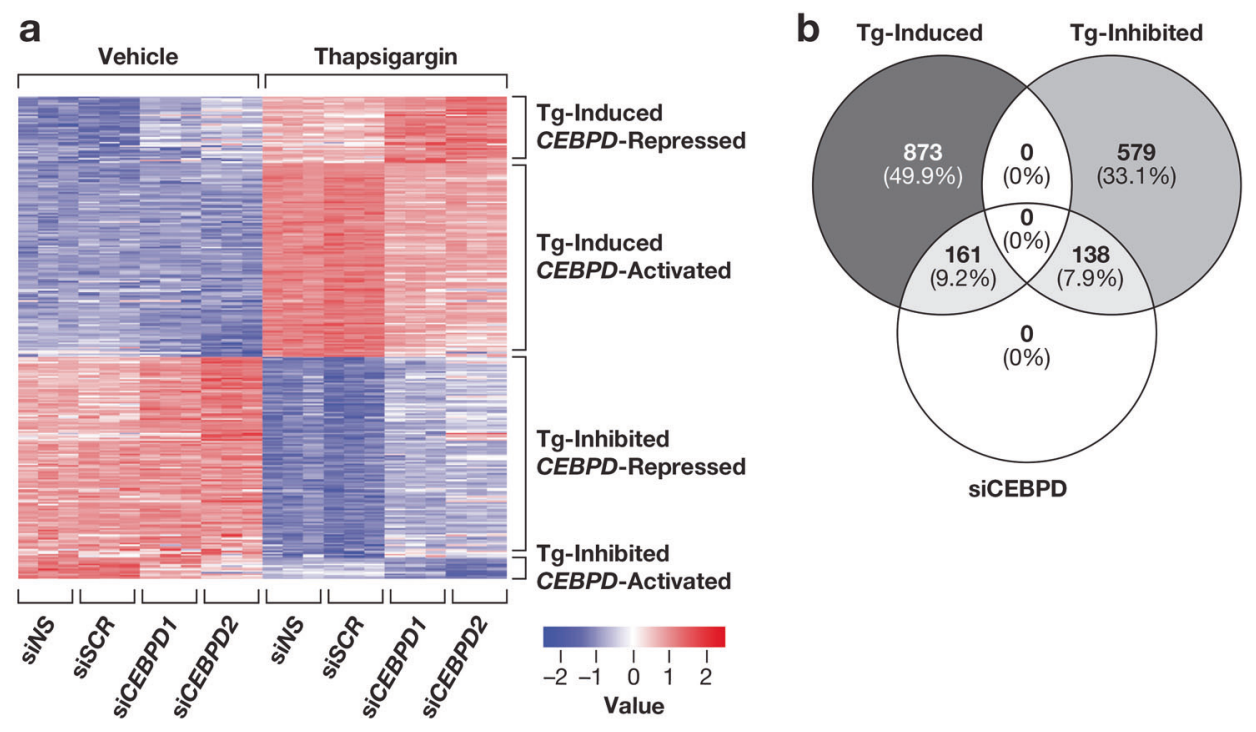

C

MDA-MB-435S

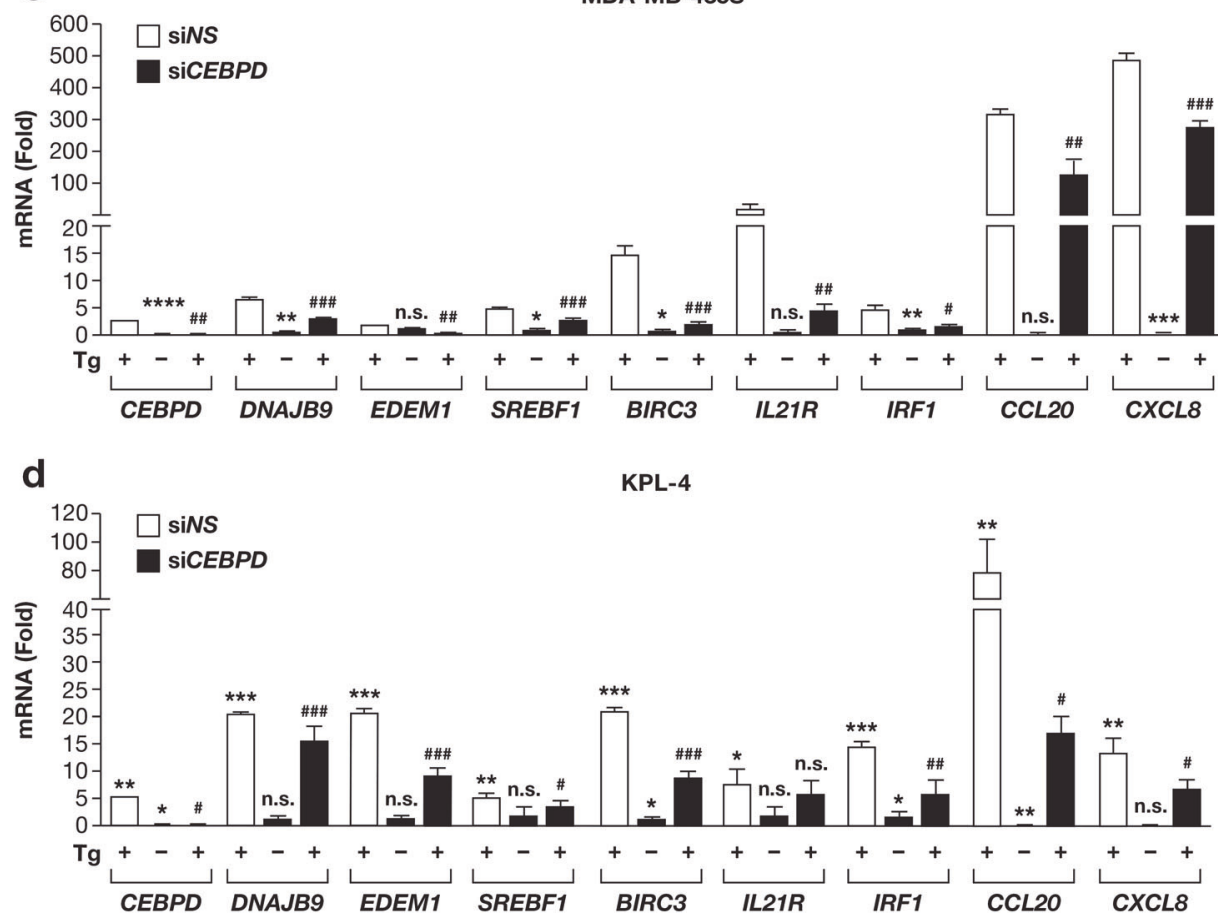

Fig. 4 C/EBPS mediates ER stress-induced changes in gene expression. a Heatmap of differentially expressed genes (DEGs) as determined by mRNA-Seq of MDA-MB-435S cells transfected with either of two independent controls (NS, SCR) or two independent CEBPD-targeting siRNAs (CEBPD1, CEBPD2) treated with vehicle or $100 \mathrm{nM} \mathrm{Tg}$ for $6 \mathrm{~h}$. Only genes that were significantly altered by Tg-treatment in control siRNA transfected cells were included in this analysis, $\mathbf{b}$ Venn diagram illustrating the number of DEGS shown in $\mathbf{a}$. c qRT-PCR analysis of select genes from a in siCEBPD1 transfected cells relative to DMSO-treated siNS control of cells treated as in a. d qRT-PCR analysis of the indicated genes in KPL-4 cells after transfection with siNS control or siCEBPD1 +2 and treated with DMSO or Tg $(100 \mathrm{nM})$ for $6 \mathrm{~h}$, relative to DMSO treated control. Quantitative data are represented as mean \pm S.E.M, $n=3 ;{ }^{*} P<0.05,{ }^{* *} P<0.01,{ }^{* * *} P<0.001,{ }^{* * *} P<0.0001$ for comparisons to siNS treated with *DMSO or \#Tg; n.s., not significant.

what extent the potential interaction of C/EBP $\delta$ with other UPR effectors [26, 57], including ATF4 [37], may be involved in the regulation of these genes. Previous reports had implicated C/EBP $\delta$ in both activation and inhibition of CCL20 and CXCL8 expression in immune cells or brain cells $[26,58]$. We show that C/EBP $\delta$ supports expression of these chemokines in cancer cells under acute ER stress as mediator of PERK activation. CXCL8 activation by C/EBP $\delta$ is also in line with its role in promoting cancer stem cells and tumor progression $[18,59]$. We focused functional studies on the CXCL8-CXCR1/2 axis because CCL20 was expressed at significantly lower levels. However, within the tumor microenvironment, such levels of CCL20 expression may be biologically significant as an autocrine factor and/or modulator of infiltrating immune cells.

Because of the janus-faced nature of PERK signaling in cancer and the toxicity of PERK inhibitors in vivo, direct inhibition of PERK is currently not attainable in the clinic [27, 60, 61]. However, inhibition of IL-8 signaling is being investigated in the clinical setting. SX-682 is in clinical trials for melanoma (NCT03161431) and other CXCR1/2 inhibitors are in trials for combination therapies in breast cancer [62-64]. Mice lack the gene encoding 
a

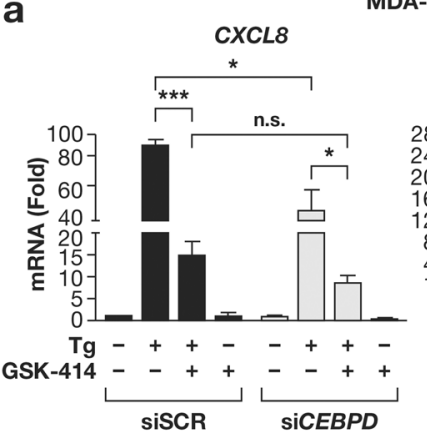

C

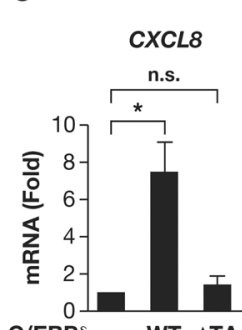

HEK293T

C/EBPS - WT $\triangle T A$

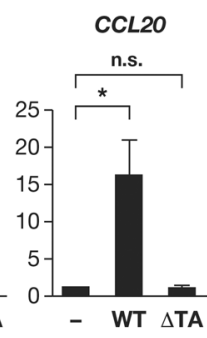

e

CXCL8
Promoter

$-110 \quad$ FLuc

\begin{tabular}{l|l}
\hline-110 & FLuc \\
\hline-110 & FLuc \\
\hline
\end{tabular}

\begin{tabular}{ll}
-65 & FLuc \\
\hline-65 & \\
\hline
\end{tabular}

\begin{tabular}{lll}
\hline-65 & FLuc \\
\hline & FLuc \\
\hline
\end{tabular}
MDA-MB-435S
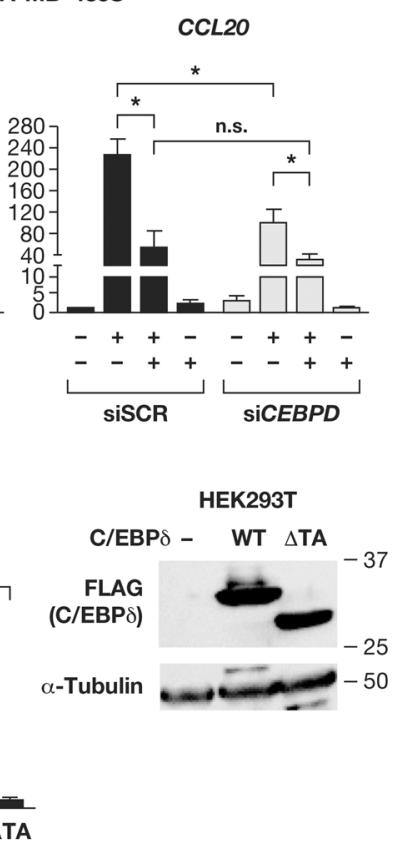

b

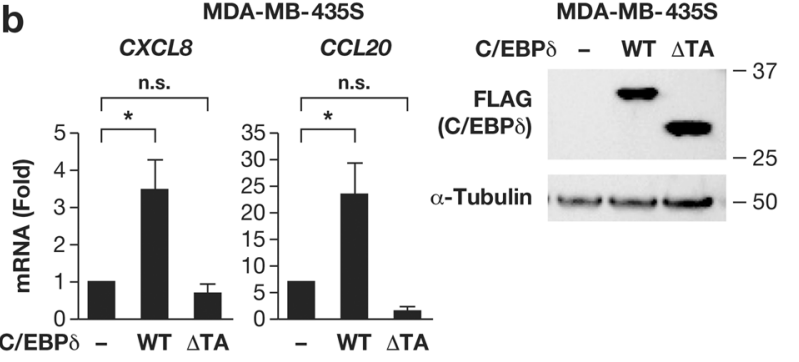

d

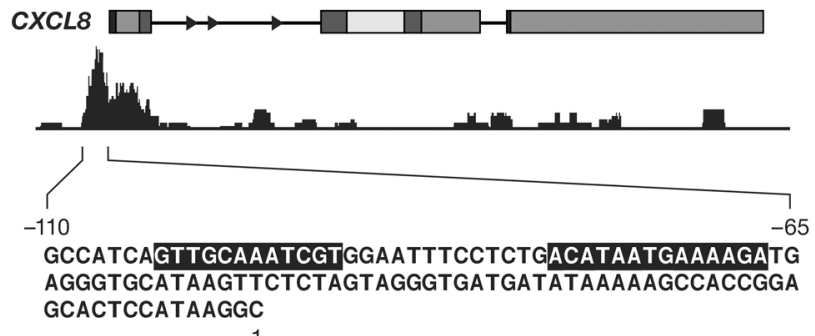

f

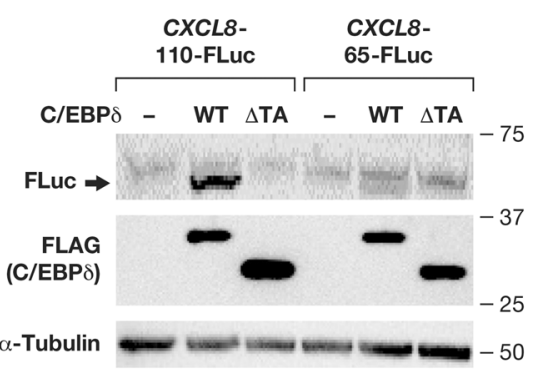

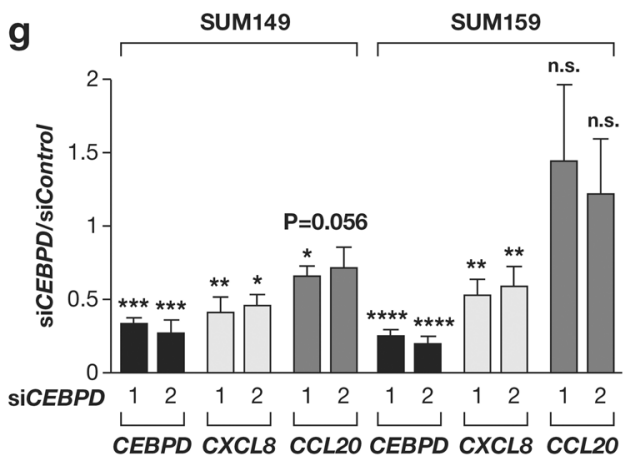

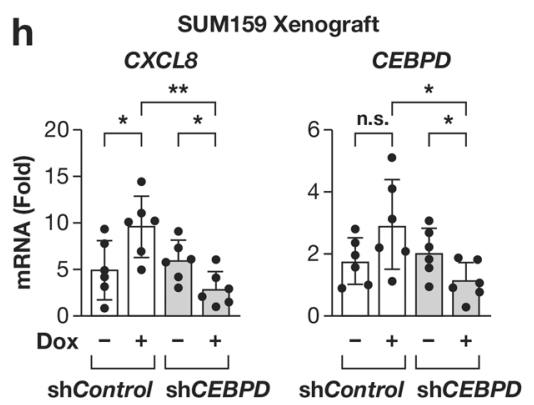

Fig. 5 C/EBPS is sufficient to induce CXCL8 and CCL20 transcription. a qRT-PCR analysis of CXCL8 and CCL20 mRNA levels in MDA-MB-435S cells transfected with siSCR or siCEBPD, treated with DMSO (-) or Tg (100 nM) for $6 \mathrm{~h}$ and with or without with GSK-414 (1 $\mu$ M) pre-treatment as indicated. b, c qRT-PCR analysis of CXCL8 and CCL20 mRNA levels in MDA-MB-435S (a) and HEK293T (b) cells transfected with expressing constructs of full length (WT) or transactivation domain-truncated ( $\triangle T A)$ C/EBPS with FLAG-tag. Empty vector was used as control. Panels on the right show Western blots to demonstrate expression of ectopic C/EBP $\delta$ proteins. d Schematic of the CXCL8 gene along with the C/EBPS ChIP-Seq track from HepG2 cells as reported by the ENCODE database, and the sequence between positions -110 and -1 harboring a peak and C/EBP motifs (shaded) and indicating the position (-65) of the deletion mutation of the reporter construct shown in e. e Luciferase reporter assay in HEK293T cells co-transfected with C/EBPS expression constructs as in $\mathbf{b}$ and Firefly luciferase (FLuc) reporter constructs containing the proximal CXCL8 promoter region from position -110 or -65 to -1 . $\mathbf{f}$ Western blot analysis of representative extracts from e showing FLuC and C/EBPS (anti-FLAG) protein expression. g qRT-PCR analysis of the mRNA levels of CEBPD, CXCL8, and CCL20 in SUM149 and SUM159 cells $72 \mathrm{~h}$ after nucleofection with control or two independent siRNAs against CEBPD. $\mathbf{h}$ qRT-PCR analysis of CXCL8 and CEBPD mRNA in SUM159 xenograft tumors with Dox-inducible shRNA and with and without Dox-treatment as described [18]. Quantitative data are mean $\pm S$. E.M; a-c, g, $n=3 ; \mathbf{e}, n=4 ; \mathbf{h}, n=6$; ${ }^{*} P<0.05,{ }^{* *} P<0.01$, ${ }^{* * *} P<0.001,{ }^{* * *} P<0.0001 ;$ n.s., not significant. 
a

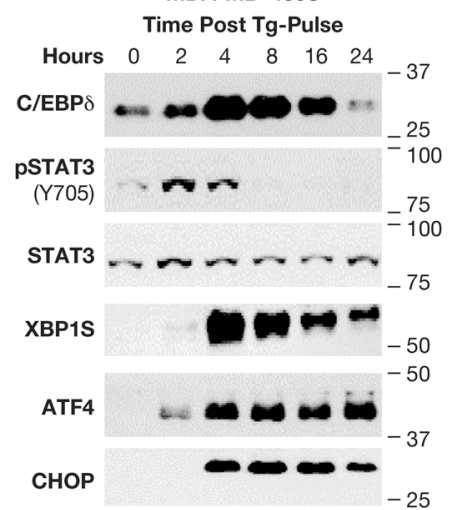

$\because \sim \sim \sim \sim-75$

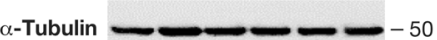

b

(6)
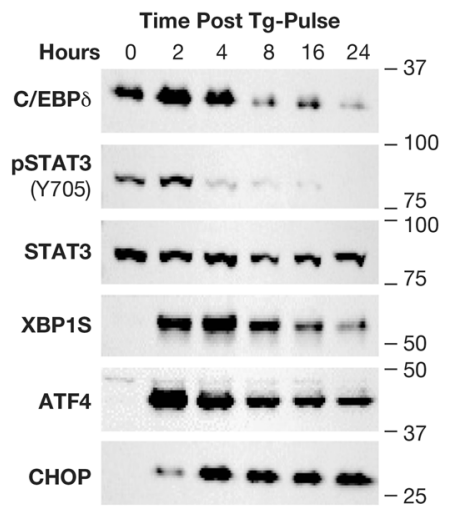

BiP $\sim \sim \sim \sim \sim \sim-75$

$\alpha$-Tubulin $\Leftrightarrow \omega \omega-50$

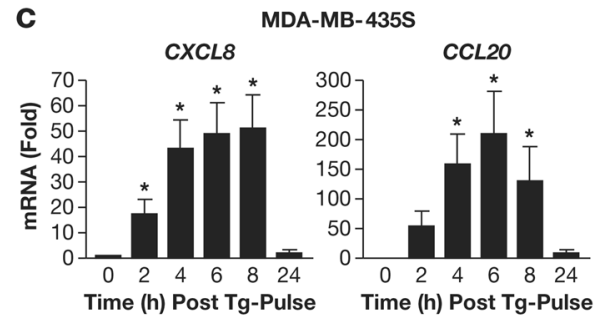

d
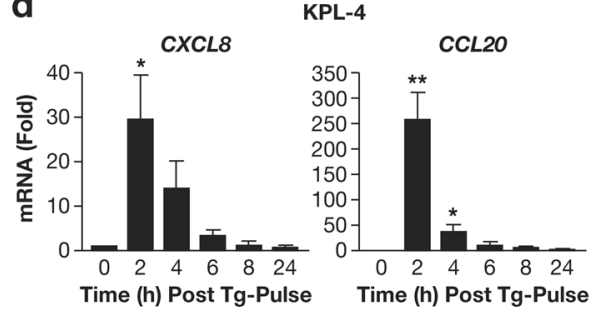
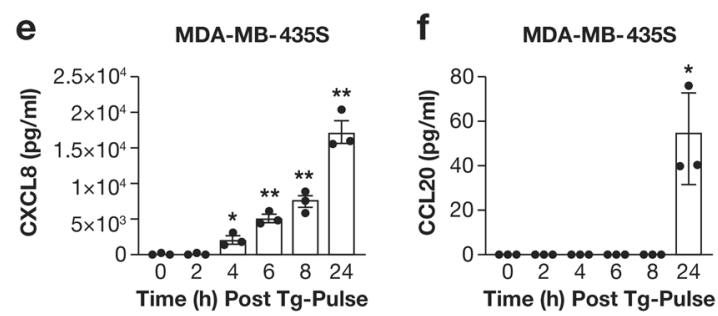

h

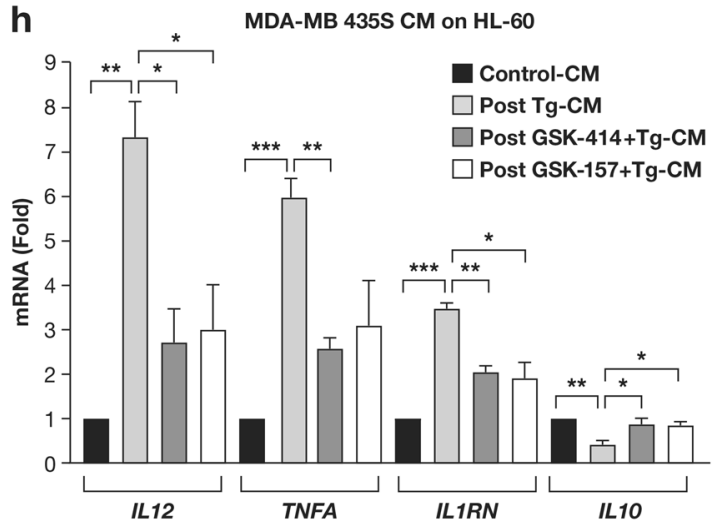

j
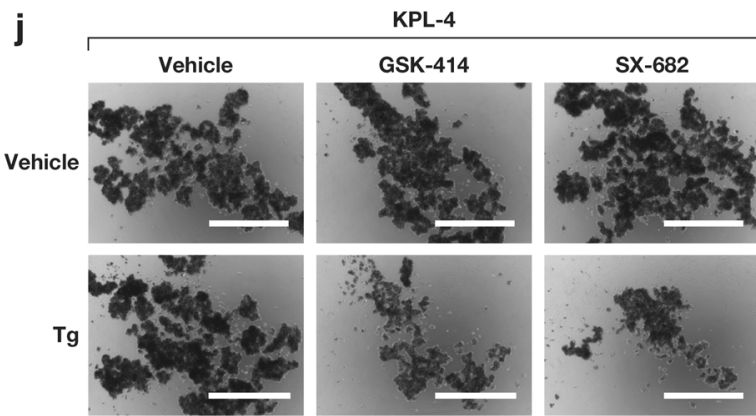

CXCL8/IL-8 and the CXCR1 receptor may not be functionally identical to human [65]. Therefore, pre-clinical studies on the role of this pathway in the tumor-microenvironment interactions are not readily feasible. Nonetheless, our findings suggest that CXCR1/ 2 inhibitors could be suitable for combination therapy with ER stress inducing agents. Many chemotherapeutics disrupt cancer
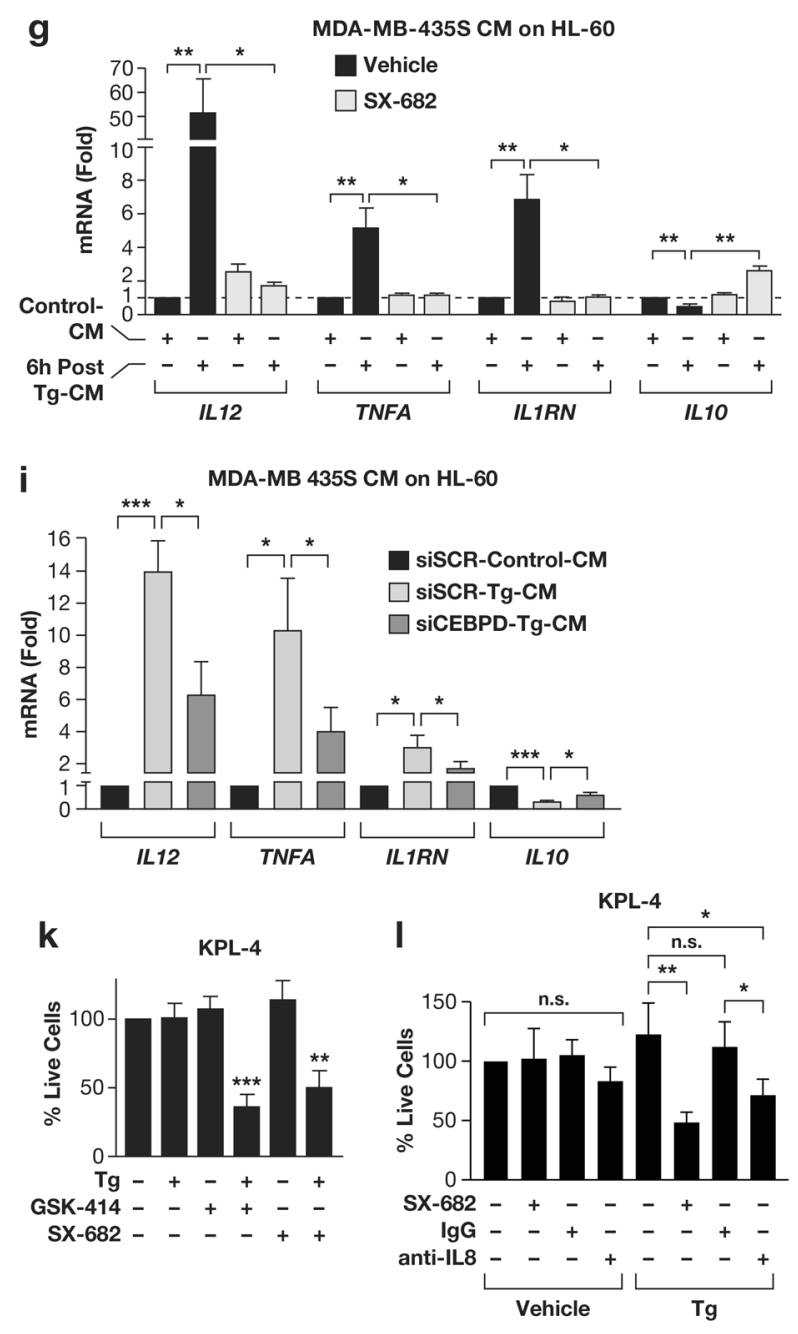

cell proteostasis and thereby cause ER stress [22]. On the other hand, the cancer cell secretome, and prominently IL- 8 , have been shown to contribute to treatment resistance $[66,67]$. Our study contributes a molecular pathway from PERK to CXCL8/IL-8 as a plausible mechanism for emergence of immune suppression and resistance in response treatment. 
Fig. 6 Transient exposure to Thapsigargin triggers long-term secretion of CXCL8 and CCL20 and modulation of immune and tumor cells. a, b Western blot analysis of the indicated proteins in (a) MDA-MB-435S and (b) KPL-4 cells treated with $100 \mathrm{nM}$ Tg for 30 min followed by removal of $\mathrm{Tg}$ and collected at indicated times thereafter $(0 \mathrm{~h}=$ pulse-treated with DMSO). $\mathbf{c}$, $\mathbf{d}$ qRT-PCR analysis of $C X C L 8$ and $C C L 20$ mRNA levels in c MDA-MB-435S and $\mathbf{d}$ KPL-4 cells treated as panels a and $\mathbf{b}$. e, $\mathbf{f}$ Enzyme-linked immunosorbent assay (ELISA) for $\mathbf{e}$ CXCL8 and f CCL20 in conditioned media from MDA-MB-435S cells treated as in a. g qRT-PCR analysis of IL12, TNFA, IL1RN and IL10 mRNA levels in HL-60 cells treated for $24 \mathrm{~h}$ with $33 \%$ of $6 \mathrm{~h}$-conditioned media from MDA-MB-435S cells pulse-treated with $100 \mathrm{nM}$ Tg for $30 \mathrm{~min}$. $\mathbf{h}$ qRT-PCR analysis of IL12, TNFA, ILIRN and IL10 mRNA levels in HL-60 cells treated for $1 \mathrm{~h}$ with $33 \%$ of $6 \mathrm{~h}$-conditioned media from MDA-MB-435S pulsetreated with $100 \mathrm{nM}$ Tg for $30 \mathrm{~min}$ and PERK inhibitors GSK-414 or GSK2656157 (GSK-157) as indicated. i qRT-PCR analysis of gene expression in HL-60 cells as in $\mathbf{h}$ using CM from MDA-MB-435S cells transfected with siRNA and pulse-treated with Tg for 30 min as indicated. $\mathbf{j}$, $\mathbf{k}$ KPL-4 cells by $\mathbf{j}$ light microscopy (Scale bar: $1 \mathrm{~mm}$ ) and $\mathbf{k}$ live cell counts on day 4 of suspension culture that was preceded by $6 \mathrm{~h}$ of the indicated treatments with Tg $(100 \mathrm{nM}), \mathrm{GSK}-414(1 \mu \mathrm{M})$, and/or SX-682 $(10 \mu \mathrm{M})$ in attachment culture (2D). I Live cell counts of KPL-4 cells on day 4 of suspension culture that was preceded by $6 \mathrm{~h}$ of the indicated treatments with Tg (100 nM), SX-682 (10 $\mu \mathrm{M}), \mathrm{lgG}(20 \mu \mathrm{g} / \mathrm{ml})$ or anti-IL8/CXCL8 $(20 \mu \mathrm{g} / \mathrm{ml})$ in attachment culture (2D). Quantitative data are represented as mean \pm S.E.M; $n=3$, except $\mathbf{i} n=4 ;{ }^{*} P<0.05,{ }^{* *} P<0.01,{ }^{* * *} P<$ $0.001,{ }^{* * * *} P<0.0001$.

\section{MATERIALS AND METHODS \\ Reagents and antibodies}

Thapsigargin (\#586005) and Tunicamycin (\#654380) were from Calbiochem, Burlington, MA, USA; PERK inhibitor GSK2606414 (GSK-414, \#5107) from Tocris Minneapolis, MN, USA; JAK inhibitors Pyridone 6 (\#420099), AZD1480 (\#SML1505) and 2-deoxy-glucose (2DG, \#D8375) from Millipore Sigma, St. Louis, MO, USA; IL-6 (\#PHC0064) from Gibco-Life Technologies Corporation, Carlsbad, CA, USA; MK-2206 (\#S1078) from Selleck Chemicals, USA); SX-682 (\#HY-119339) and GSK-157 (GSK2656157, \#HY-13820) from MedChemExpress, Monmouth Junction, NJ, USA; Ruxolitinib (\#DC4230) from DC Chemicals, Shanghai, China; U0126 (\#V112A) from Promega, Madison, WI, USA; rapamycin (\#R-5000) from LC Laboratories, Woburn, MA, USA. 2DG was diluted in water, and all other agents in DMSO. Antibodies were obtained from Cell Signaling, Danvers, MA, USA (PERK, \#3192; phospho-STAT3, \#9145; STAT3, \#4904; Phospho-Erk1/2, \#9106; phosphoAkt, \#4060; Akt, \#4691; phospho-p70 S6 Kinase, \#9234; p70 S6 Kinase, \#9202; anti-mouse HRP, \#7076; Anti-rabbit-HRP, \#7074); Novus, Centennial, CO, USA (HIF-1a, \#NB100-449); Santa Cruz Biotechnology, Dallas, Texas, USA (ATF4, sc-390063; CHOP, sc-4066; GAPDH， sc-47724; C/EBPS, sc135733); BD Pharmingen, San Jose, CA, USA (BiP, 610978); Biolegend, San Diego, CA, USA (XBP1S, 619502); Rockland, Limerick, PA, USA (Tubulin, 600401-880); Promega (Fluc, G7451); Developmental Studies Hybridoma Bank, lowa City, IA, USA (alpha-tubulin, \#12G10, deposited by Frankel, J. / Nelsen, E.M); Millipore Sigma (anti-FLAG, \#F1804), and R\&D systems, Flanders, NJ, USA (anti-hCXCL8/IL-8, \#AB-208-NA, lgG, \#AB-108-C).

\section{Cell lines and culture}

MDA-MB-435S, MDA-MB-231, MDA-MB-468, BT-549, HEK293T, HL-60 and MCF-7 originated from ATCC, Manassas, VA, USA. SUM149 and SUM159 cells originated from Asterand Bioscience. KPL-4 cells were established by Dr. Junichi Kurebayashi (Kawasiki Medical School) and kindly provided by Dr. Naoto Ueno (MDACC). All cell lines were routinely tested for mycoplasma and were authenticated bi-annually by Genetica (Labcorp, Burlington, NC, USA). Cells were cultured in DMEM supplemented with $10 \%$ fetal bovine serum (FBS) and 1\% Penicillin-Streptomycin, except KPL-4 (DMEM/F12), HL-60 (RPMI), and SUM149 (Ham's F-12 with $5 \mu \mathrm{g} / \mathrm{ml}$ hydrocortisone and $1 \mu \mathrm{g} / \mathrm{ml}$ Insulin). For MCF-7 and HEK293T, the medium was supplemented with $1 \mathrm{mM}$ sodium pyruvate. MCF10A and MCF12A were cultured in DMEM + F12 GlutaMax supplemented with $5 \%$ FBS, $10 \mathrm{mg} / \mathrm{ml}$ Insulin (Millipore Sigma \#10516), $100 \mathrm{ng} / \mathrm{ml}$ Cholera toxin (Millipore Sigma \#227036), $0.5 \mathrm{mg} / \mathrm{ml}$ Hydrocortisone (Millipore Sigma \#H4001), $20 \mathrm{ng} / \mathrm{ml}$ EGF (Invitrogen, Carlsbad, CA, USA, \#13247-051) and $1 \mathrm{mM} \mathrm{CaCl} 2$. Pre-treatments with inhibitors were for 30 min except SX-682 (15 min). Vehicle was used as control in all experiments. For anoxic treatment, cells were cultured $24 \mathrm{~h}$ in an anaerobic chamber with $0.1 \% \mathrm{O}_{2}$. For glucose deprivation (GD), complete medium was removed, cells were washed twice with PBS followed by culture in no-glucose-DMEM (Thermo Scientific \#11966025) supplemented with 10\% dialyzed FBS (Thermo Scientific \# A3382001) and 1\% Penicillin-Streptomycin.

For suspension culture, 100,000 KPL-4 cells were first seeded in 6 well plates and the next day treated with GSK-414 $(1 \mu \mathrm{M})$ and/or SX-682 $(10 \mu \mathrm{M})$, and/or anti-hCXCL8/IL8 $(20 \mu \mathrm{g} / \mathrm{ml})$ and/or anti-lgG for $30 \mathrm{~min}$ prior to exposure to thapsigargin $(100 \mathrm{nM})$ for $6 \mathrm{~h}$. Cells were washed, trypsinized, and 2500 cells were seeded in 24 well ultra-low attachment plates (CORNING, St. Louis, MO, USA, \#3473) in MammoCult medium supplemented with heparin and hydrocortisone (STEMCELL Technologies Seattle, WA, USA, \#05620, \#07925, \#07980). After 4 days of suspension culture, cells were collected and centrifuged at $1000 \mathrm{rpm}$ for $1 \mathrm{~min}$ and washed once with PBS. Cells were suspended in $0.5 \mathrm{ml}$ culture medium and live cells were counted based on trypan blue dye-exclusion method.

Pulse treatment and condition media preparation. At about $70 \%$ confluence, cells were incubated with $100 \mathrm{nM}$ thapsigargin $(\mathrm{Tg})$ or $0.1 \%$ DMSO for $30 \mathrm{~min}$ followed by removal of the media. As applicable, inhibitors were added 30 min before Tg. Cells were washed twice with warm PBS, and then incubated with fresh medium for the indicated time points. Conditioned medium (CM) was collected, centrifuged for $10 \mathrm{~min}$ at $300 \mathrm{~g}$ to remove any cells. Target cells were incubated with a final concentration of $33 \%(\mathrm{v} / \mathrm{v}) \mathrm{CM}$ for the indicated times. Time points for subsequent analyses were chosen based on the expression kinetics of the genes/proteins of interest in the respective cell lines and treatment paradigms.

\section{Transient transfections and RNAi}

Cells were transfected with siRNA by nucleofection using the Amaxa Cellline Nucleofector Kit V (Cat\# VCA-1003; Lonza AG). Controls were Scrambled siRNA (SCR) (\#D-001960-01-05, Dharmacon, Lafayette, CO, USA) or EGFP oligonucleotides (NS; 5'-CAAGCTGACCCTGAAGTTC-3') [68]. Transfected cells were re-seeded $48 \mathrm{~h}$ post-transfection and allowed to attach overnight before starting treatments.

siRNA sequences for $C E B P D$ were as follows:

CEBPD siRNA-1-sense $5^{\prime}$-rUrCrGrCrCrGrArCrCrUrCrUrUrCrArArCrArGTT-3' CEBPD siRNA-1-antisense 5'-rCrUrGrUrUrGrArArGrArGrGrUrCrGrGrCrGrATT-3' CEBPD siRNA2-sense 5'-rCrCrArCrUrArArArCrUrGrCrGrArGrArGrArATT-3' CEBPD siRNA2-antisense 5'-rCrUrGrUrUrGrArArGrArGrGrUrCrGrGrCrGrATT-3' siRNA pools for ATF6A/ATF6a (sc-37699), ERN1/IRE1a (sc-40705), EIF2AK3/ PERK (sc-36213), NRF2 (sc-37030) and STAT3 (sc-29493) were purchased from Santa Cruz Biotechnology.

\section{RNA isolation and qRT-PCR}

RNA was isolated using GeneJET RNA purification kit (Thermo Fisher Waltham, MA, USA), and CDNA was synthesized with Superscript reverse transcriptase III (RT) according to the manufacturer's instructions (Invitrogen, CA). RNA samples of SUM159 cell xenograft tumors with Dox-inducible shRNA were as described [18]. qRT-PCR was performed with appropriate primer sets as described in Table S3 using Fast SYBR Green master mix (Applied Biosystems, Foster City, CA, USA) on the 7500 Fast or QuantStudio 5 Real Time PCR instrument (Applied Biosystems). Fold changes were analyzed using $\mathrm{ddCt}$ method and normalized to GAPDH or RPLPO. All reactions were performed in triplicates and the data are represented as mean \pm S.E.M of at least three independent experiments as indicated.

\section{mRNA-Seq analysis and public data source}

MDA-MB-435S cells were transfected with the indicated siRNA, $48 \mathrm{~h}$ later cells were treated with DMSO or $100 \mathrm{nM}$ thapsigargin for $6 \mathrm{~h}$ and RNA was isolated using the RNAeasy kit (Qiagen, Germantown, MD, USA). mRNA-Seq analysis was carried out on samples from three biological replicates. Library preparation was done by following standard IlluminaTruSeq protocol FC122-1001 with barcoding. The 24 samples were pooled and sequenced on two lanes of HiSeq2500 with Illumina TruSeq V4 chemistry, which yielded $\sim 40$ million strand-specific paired-end 125 bp reads with $>91 \%$ bases having call quality of Q30 or above per sample. Both reads of the samples 
a

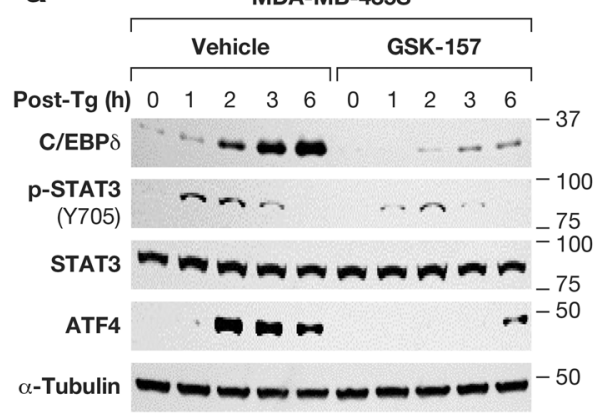

C

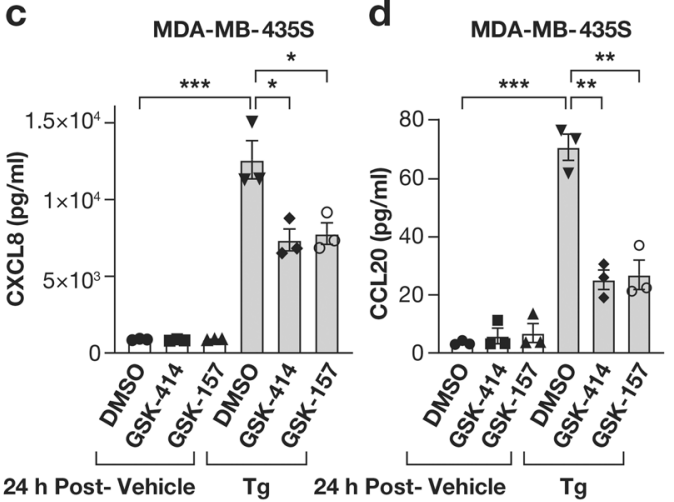

b

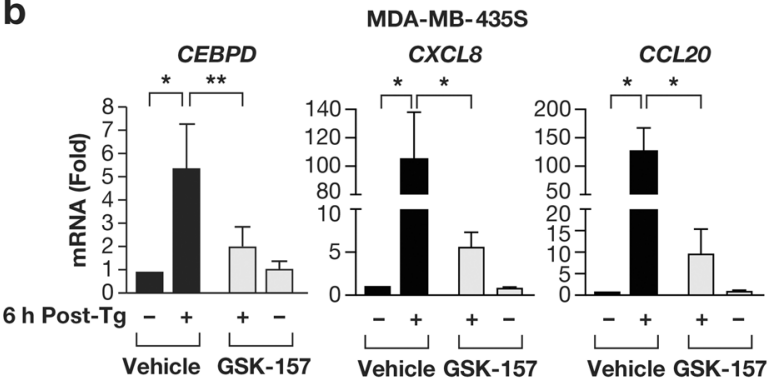

e

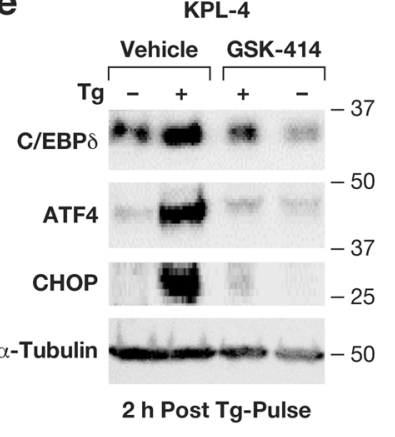

f

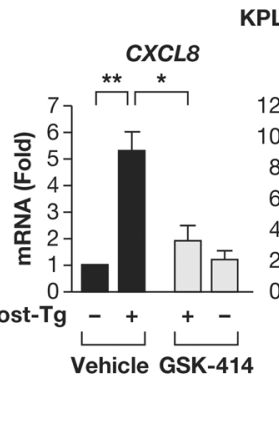

KPL-4

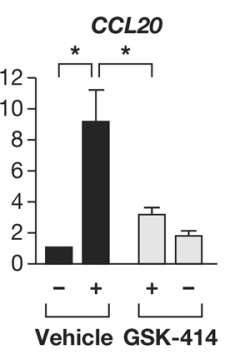

g

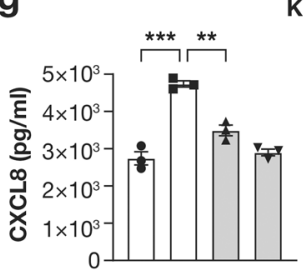

6 h Post-Tg $\underset{\text { Vehicle }}{-}+\underset{\text { GSK-414 }}{+}$
KPL-4

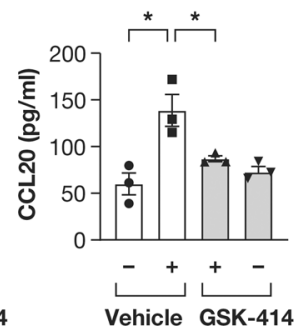

h

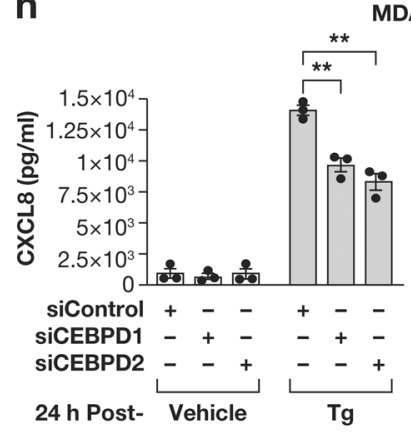

MDA-MB-435S

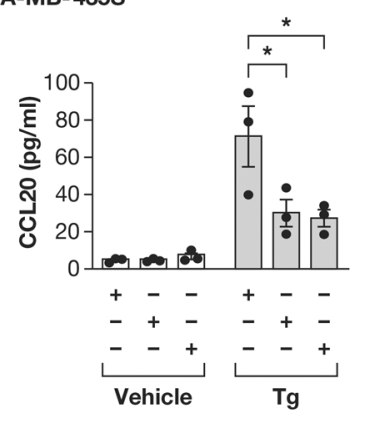

i
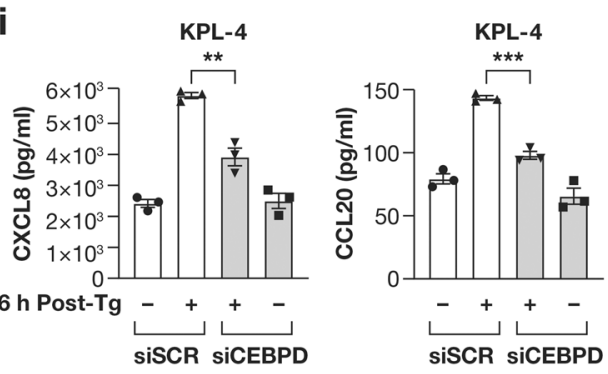

Fig. 7 PERK and C/EBPS contribute to chemokine expression following ER stress. a Western blot analysis of the indicated proteins from MDA-MB-435S cells collected at the indicated times after pulse-treatment with $100 \mathrm{nM} \mathrm{Tg}$ for 30 min with or without pre-treatment with GSK$157(10 \mu \mathrm{M})$. b qRT-PCR analysis of CEBPD, CXCL8 and CCL20 mRNA level in MDA-MB-435S cells $6 \mathrm{~h}$ after pulse-treatment as in a. c, d ELISA for c CXCL8 and d CCL20 in $24 \mathrm{~h}$ conditioned media of MDA-MB-435S cells pulse-treated as in a. e Western blot analysis of indicated proteins from KPL-4 cells $2 \mathrm{~h}$ after pulse-treatment with $100 \mathrm{nM} \mathrm{Tg}$ with or without 30 min pre-treatment with $1 \mu \mathrm{M}$ GSK-414. f qRT-PCR analysis of CXCL8 and CCL20 mRNA level from KPL-4 cells treated as in e. g ELISA of CXCL8 and CCL20 in $6 \mathrm{~h}$ conditioned media from KPL-4 cells treated as panel e. $\mathbf{h}$ ELISA of CXCL8 and CCL20 in $24 \mathrm{~h}$ conditioned media from MDA-MB-435S cells transfected with either control siRNA or two independent siRNAs against CEBPD and pulse treated with $100 \mathrm{nM} \mathrm{Tg.} \mathrm{i}$ ELISA of CXCL8 and CCL20 in $6 \mathrm{~h}$ conditioned media from KPL4 cells transfected with either siSCR or siCEBPD and pulse treated with $100 \mathrm{nM}$ Tg. Quantitative data are represented as mean $\pm S . E . M, n=3,{ }^{*} P<0.05,{ }^{* *} P<0.01$, ${ }^{* * *} P<0.001$. 


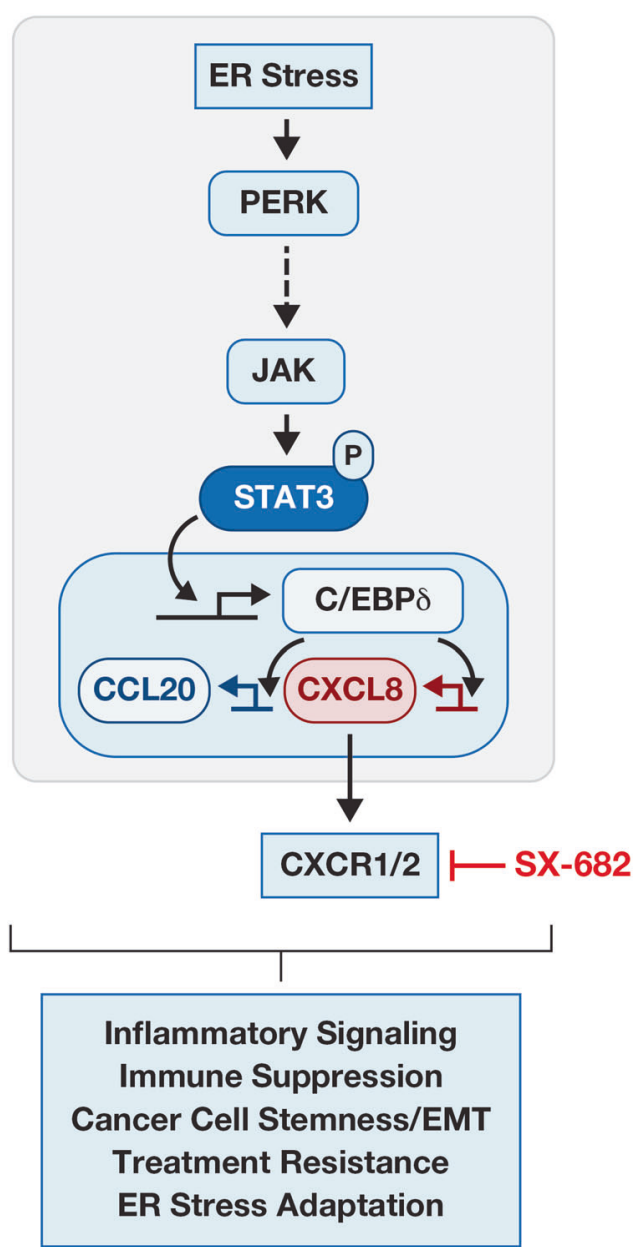

Fig. 8 Model summarizing the pathway described in this study along with known effects of CCL20 and CXCL8 signaling in the context of cancer. Some of the relationships in this linear pathway may be the result of indirect mechanisms (indicated by dotted line) and/or also include the contribution of additional co-factors (not shown).

were trimmed for adapters and low-quality bases using Trimmomatic software (version 0.30). The trimmed fastq data were aligned to human genome hg19 with STAR (version 2.4.2a), which used GENCODE gtf file version 19 (Ensembl 74). STAR software also generated the strand-specific gene read counts. About $80 \%$ of $\sim 40$ million reads per sample were mapped to the human genome uniquely for a total of $\sim 87 \%$ mapping rate. The read counts for each gene from STAR were normalized with R Package limma (version 3.26.8). The differentially expressed genes between treated and control groups were analyzed with linear mixture models in $\mathrm{R}$ package Ime4 (version 1.1-12). The heatmap display of manually curated genes with FDR $<0.05$ between treated and control groups was generated with $R$ packages gplots (version 3.0.1). The mRNA-Seq data are available at the NCBI Gene Expression Omnibus under accession number GSE131048. The Venn diagram was generated with the public software Venny (Oliveros, J.C. (2007-2015) at https://bioinfogp.cnb.csic.es/tools/venny/index.html.

\section{In silico ChIP analysis}

Transcription factor binding regions (TFBRs) for the C/EBP family on the human genome (hg38) were obtained from meta-clusters reported in the Gene Transcription Regulation Database (https://gtrd.biouml.org/) [69]. These TFBRs were intersected with promoter regions of protein-coding genes, which were defined as $2 \mathrm{~kb}$ upstream and $500 \mathrm{bp}$ downstream from the transcription-start-sites (TSS). Human gene annotations release 30 for hg38 from Genecode (https://www.gencodegenes.org/human/release_30. html) was used to determine TSSs. This analysis yielded a total of 15,591 genes, with an overlap of 247 genes in common with the mRNA-Seq DEGs as defined in Fig. 4a. ENCODE data for C/EBPS binding to the CXCL8 promoter were generated with an anti-Flag tag antibody against endogenously tagged CEBPD (ENCSR520MCD at www.encodeproject.org).

\section{Western blotting}

All Western data were generated from whole cell lysates. Cells were scraped into medium and pelleted by centrifugation along with the floating population, washed once with cold PBS, lysed with $2 x$ Laemmli sample buffer (Bio-Rad Laboratories, Hercules CA, USA) and heated at $100^{\circ} \mathrm{C}$ for $5 \mathrm{~min}$. Proteins were quantified using the Pierce 660 Protein Assay kit (Thermo Fisher Scientific, \#22662) and loaded onto 4-20\% SDS polyacrylamide gels (Invitrogen). After electrophoresis, proteins were transferred to nitrocellulose membrane and blocked with $5 \%$ non-fat dry milk in Tris Buffered Saline (TBS). Immunodetection was performed with the indicated primary antibodies for overnight incubation at $4{ }^{\circ} \mathrm{C}$. Following washing and incubation with the appropriate HRP-conjugated secondary antibodies, signals were visualized by Supersignal West Dura Extended Duration substrate (\#34076, Pierce, Rockford, IL, USA) or ProSignal Femto ECL reagent (\#20-302, Genesee Scientific, El Cajon, CA, USA). All western analysis data are representative of at least three independent biological replications. Quantifications were done by ImageJ (https://imagej.nih.gov/ij/). After background subtraction, PSTAT3 data were normalized to STAT3 total protein and graphed as fold change with respect to untreated control from at least three independent experiments.

\section{Enzyme-linked immunosorbent assay}

ELISA assays with conditioned media were performed using ELISA assay kits from R\&D Systems (CXCL8 \#D8000C, CCL20 \#DM3A00) as per manufacturer's instruction. Optical density of the products was measured with a SpectraMax iD3 instrument at $450 \mathrm{~nm}$ with a correction wavelength at $570 \mathrm{~nm}$. Concentrations were estimated using standard curves generated with provided purified protein standards.

\section{Cloning of reporter and expression constructs and luciferase reporter assay}

To mutate the transactivation domain of full-length Flag-tagged C/EBP $\delta$ [70], residues 45-85 were deleted by site directed mutagenesis (Agilent, Santa Clara, CA, USA, \#210518) using the following primers: 5'GGGGCCCTA GGCGAGTTCAACAGCAATCACA-3' and 5'-TGTGATTGCTGTTGAACTCGCC TAGGGCCCC-3'. The CXCL8 promoter regions were amplified from human genomic DNA with the following primers: IL8p-Fw1-Xhol (for -110: $5^{\prime}-$ ACTCGAGCCATCAGTTGCAAATCGTG-3') or IL8p-Fw2-Xhol (for -65: $5^{\prime}$ - ACT CGAGGGTGCATAAGTTCTCTAGT-3') and IL8p-Rev-HindIII (5'-TAAGCTTG CCTTATGGAGTGCTCCGGT-3') and cloned into pGL3-Basic vector (Promega, E1751). HEK293T cells were co-transfected with CXCL8 promoter reporter constructs along with C/EBPS expression constructs [70]. Renilla luciferase expression plasmid, pRL-CMV (Promega E2261) was used as an internal transfection control. Dual luciferase activity was assessed $48 \mathrm{~h}$ after transfection from equal amounts of total protein using Dual Luciferase assay kit (Promega, E1910) according to the manufacturer's protocol. Luminescence was measured using a SpectraMax iD3 instrument.

\section{Statistical analysis}

Unless stated otherwise, quantitative data were analyzed by the twotailed unequal variance $t$-test and are shown as mean \pm S.E.M of at least three independent biological replicates using GraphPad Prism, version 8, La Jolla California USA. $p$-values ${ }^{*} P<0.05,{ }^{*} P<0.01,{ }^{* *} P<0.001$, ${ }_{* * * *} P<0.0001$ are designated as statistically significant and $P \geq 0.05$ are designated as not significant (n.s.).

\section{DATA AVAILABILITY}

The mRNA-Seq data are available at the NCBI Gene Expression Omnibus under accession number GSE131048.

\section{REFERENCES}

1. Luo B, Lee AS. The critical roles of endoplasmic reticulum chaperones and unfolded protein response in tumorigenesis and anticancer therapies. Oncogene. 2013;32:805-18.

2. Hetz C. The unfolded protein response: controlling cell fate decisions under ER stress and beyond. Nat Rev Mol Cell Biol. 2012;13:89-102. 
3. Chevet E, Cameron PH, Pelletier MF, Thomas DY, Bergeron JJ. The endoplasmic reticulum: integration of protein folding, quality control, signaling and degradation. Curr Opin Struct Biol. 2001;11:120-4.

4. Harding HP, Calfon M, Urano F, Novoa I, Ron D. Transcriptional and translational control in the Mammalian unfolded protein response. Annu Rev Cell Dev Biol. 2002:18:575-99.

5. Kaufman RJ. Orchestrating the unfolded protein response in health and disease. J Clin Invest. 2002;110:1389-98.

6. Chen X, lliopoulos D, Zhang Q, Tang Q, Greenblatt MB, Hatziapostolou M, et al XBP1 promotes triple-negative breast cancer by controlling the HIF1alpha pathway. Nature. 2014;508:103-7.

7. Urra $H$, Dufey $E$, Avril $T$, Chevet $E$, Hetz $C$. Endoplasmic reticulum stress and the Hallmarks of cancer. Trends Cancer. 2016;2:252-62.

8. Zinszner $H$, Kuroda $M$, Wang $X$, Batchvarova $N$, Lightfoot RT, Remotti $H$, et al. CHOP is implicated in programmed cell death in response to impaired function of the endoplasmic reticulum. Genes Dev. 1998;12:982-95.

9. Schonthal $\mathrm{AH}$. Targeting endoplasmic reticulum stress for cancer therapy. Front Biosci. 2012;4:412-31.

10. Mahalingam D, Wilding G, Denmeade S, Sarantopoulas J, Cosgrove D, Cetnar J, et al. Mipsagargin, a novel thapsigargin-based PSMA-activated prodrug: results of a first-in-man phase I clinical trial in patients with refractory, advanced or metastatic solid tumours. Br J Cancer. 2016;114:986-94.

11. Mahalingam D, Peguero J, Cen P, Arora SP, Sarantopoulos J, Rowe J, et al. A phase II, multicenter, single-arm study of mipsagargin (G-202) as a second-line therapy following sorafenib for adult patients with progressive advanced hepatocellular carcinoma. Cancers. 2019;11:833.

12. Salminen A, Kaarniranta K, Kauppinen A. ER stress activates immunosuppressive network: implications for aging and Alzheimer's disease. J Mol Med. 2020;98:633-50

13. Chen X, Cubillos-Ruiz JR. Endoplasmic reticulum stress signals in the tumour and its microenvironment. Nat Rev Cancer. 2020;21:71-88.

14. Jiang Z, Zhang G, Huang L, Yuan Y, Wu C, Li Y. Transmissible endoplasmic reticulum stress: a novel perspective on tumor immunity. Front Cell Dev Biol. 2020;8:846

15. Balamurugan $\mathrm{K}$, Sterneck $\mathrm{E}$. The many faces of C/EBPdelta and their relevance for inflammation and cancer. Int J Biol Sci. 2013;9:917-33.

16. Litvak V, Ramsey SA, Rust AG, Zak DE, Kennedy KA, Lampano AE, et al. Function of C/EBPdelta in a regulatory circuit that discriminates between transient and persistent TLR4-induced signals. Nat Immunol. 2009;10:437-43.

17. Pawar SA, Shao L, Chang J, Wang W, Pathak R, Zhu X, et al. C/EBPdelta deficiency sensitizes mice to ionizing radiation-induced hematopoietic and intestinal injury. PLoS ONE. 2014;9:e94967.

18. Balamurugan K, Mendoza-Villanueva D, Sharan S, Summers GH, Dobrolecki LE, Lewis MT, et al. C/EBPdelta links IL- 6 and HIF-1 signaling to promote breast cancer stem cell-associated phenotypes. Oncogene. 2019;38:3765-80.

19. Rae JM, Creighton CJ, Meck JM, Haddad BR, Johnson MD. MDA-MB-435 cells are derived from M14 melanoma cells-a loss for breast cancer, but a boon for melanoma research. Breast Cancer Res Treat. 2007;104:13-19.

20. Okada T, Haze K, Nadanaka S, Yoshida H, Seidah NG, Hirano Y, et al. A serine protease inhibitor prevents endoplasmic reticulum stress-induced cleavage but not transport of the membrane-bound transcription factor ATF6. J Biol Chem. 2003;278:31024-32.

21. Sarkar TR, Sharan S, Wang J, Pawar SA, Cantwell CA, Johnson PF, et al. Identification of a Src tyrosine kinase/SIAH2 E3 ubiquitin ligase pathway that regulates C/EBPdelta expression and contributes to transformation of breast tumor cells. Mol Cell Biol. 2012;32:320-32.

22. Garg AD, Maes $H$, van Vliet AR, Agostinis $P$. Targeting the hallmarks of cancer with therapy-induced endoplasmic reticulum (ER) stress. Mol Cell Oncol. 2015;2: e975089.

23. Koumenis C, Wouters BG. "Translating" tumor hypoxia: unfolded protein response (UPR)-dependent and UPR-independent pathways. Mol Cancer Res. 2006;4:423-36.

24. Axten JM, Medina JR, Feng Y, Shu A, Romeril SP, Grant SW, et al. Discovery of 7methyl-5-(1-\{[3-(trifluoromethyl)phenyl]acetyl\}-2,3-dihydro-1 H-indol-5-yl)-7H-p yrrolo[2,3-d]pyrimidin-4-amine (GSK2606414), a potent and selective first-in-class inhibitor of protein kinase $\mathrm{R}$ (PKR)-like endoplasmic reticulum kinase (PERK). J Med Chem. 2012;55:7193-207.

25. Blais JD, Filipenko V, Bi M, Harding HP, Ron D, Koumenis C, et al. Activating transcription factor 4 is translationally regulated by hypoxic stress. Mol Cell Biol. 2004;24:7469-82

26. Li C, Fan Q, Quan H, Nie M, Luo Y, Wang L. The three branches of the unfolded protein response exhibit differential significance in breast cancer growth and stemness. Exp Cell Res. 2018;367:170-85.

27. Pytel D, Majsterek I, Diehl JA. Tumor progression and the different faces of the PERK kinase. Oncogene. 2016;35:1207-15.
28. Bellacosa A, Chan TO, Ahmed NN, Datta K, Malstrom S, Stokoe D, et al. Akt activation by growth factors is a multiple-step process: the role of the $\mathrm{PH}$ domain. Oncogene. 1998;17:313-25.

29. Meares GP, Liu Y, Rajbhandari R, Qin H, Nozell SE, Mobley JA, et al. PERKdependent activation of JAK1 and STAT3 contributes to endoplasmic reticulum stress-induced inflammation. Mol Cell Biol. 2014;34:3911-25.

30. Darnell JE Jr, Kerr IM, Stark GR. Jak-STAT pathways and transcriptional activation in response to IFNs and other extracellular signaling proteins. Science. 1994;264:1415-21.

31. Schust J, Sperl B, Hollis A, Mayer TU, Berg T. Stattic: a small-molecule inhibitor of STAT3 activation and dimerization. Chem Biol. 2006;13:1235-42.

32. Poria DK, Sheshadri N, Balamurugan K, Sharan S, Sterneck E. The STAT3 inhibitor Stattic acts independently of STAT3 to decrease histone acetylation and modulate gene expression. J Biol Chem. 2020;296:100220.

33. Johnson DE, O'Keefe RA, Grandis JR. Targeting the IL-6/JAK/STAT3 signalling axis in cancer. Nat Rev Clin Oncol. 2018;15:234-48.

34. Oslowski CM, Urano F. Measuring ER stress and the unfolded protein response using mammalian tissue culture system. Methods Enzymol. 2011;490:71-92.

35. Kramer A, Green J, Pollard J Jr, Tugendreich S. Causal analysis approaches in ingenuity pathway analysis. Bioinformatics. 2014;30:523-30.

36. Makhov P, Naito S, Haifler M, Kutikov A, Boumber Y, Uzzo RG, et al. The convergent roles of NF-kappaB and ER stress in sunitinib-mediated expression of pro-tumorigenic cytokines and refractory phenotype in renal cell carcinoma. Cell Death Dis. 2018;9:374

37. Puschel F, Favaro F, Redondo-Pedraza J, Lucendo E, lurlaro R, Marchetti S, et al. Starvation and antimetabolic therapy promote cytokine release and recruitment of immune cells. Proc Natl Acad Sci USA. 2020;117:9932-41.

38. Chang LH, Huang HS, Wu PT, Jou IM, Pan MH, Chang WC, et al. Role of macrophage CCAAT/enhancer binding protein delta in the pathogenesis of rheumatoid arthritis in collagen-induced arthritic mice. PLoS ONE. 2012;7:e45378.

39. Matsumoto T, Uchiumi T, Monji K, Yagi M, Setoyama D, Amamoto R, et al. Doxycycline induces apoptosis via ER stress selectively to cells with a cancer stem cell-like properties: importance of stem cell plasticity. Oncogenesis. 2017;6:397.

40. Kadomoto S, Izumi K, Mizokami A. The CCL20-CCR6 axis in cancer progression. Int J Mol Sci. 2020;21:5186.

41. Waugh DJ, Wilson C. The interleukin-8 pathway in cancer. Clin Cancer Res. 2008;14:6735-41.

42. Mahadevan NR, Rodvold J, Sepulveda H, Rossi S, Drew AF, Zanetti M. Transmission of endoplasmic reticulum stress and pro-inflammation from tumor cells to myeloid cells. Proc Natl Acad Sci USA. 2011;108:6561-6.

43. Sagara Y, Wade JB, Inesi G. A conformational mechanism for formation of a deadend complex by the sarcoplasmic reticulum ATPase with thapsigargin. J Biol Chem. 1992;267:1286-92.

44. Inesi G, Sagara Y. Thapsigargin, a high affinity and global inhibitor of intracellular Ca2+ transport ATPases. Arch Biochem Biophys. 1992;298:313-7.

45. Lu X, Horner JW, Paul E, Shang X, Troncoso P, Deng P, et al. Effective combinatorial immunotherapy for castration-resistant prostate cancer. Nature. 2017;543:728-32.

46. Ball ED, McDermott J, Griffin JD, Davey FR, Davis R, Bloomfield CD. Expression of the three myeloid cell-associated immunoglobulin G Fc receptors defined by murine monoclonal antibodies on normal bone marrow and acute leukemia cells. Blood. 1989;73:1951-6.

47. Dai X, Jayapal M, Tay HK, Reghunathan R, Lin G, Too CT, et al. Differential signal transduction, membrane trafficking, and immune effector functions mediated by FcgammaRI versus FcgammaRlla. Blood. 2009;114:318-27.

48. Alfaro C, Sanmamed MF, Rodriguez-Ruiz ME, Teijeira A, Onate C, Gonzalez A, et al. Interleukin-8 in cancer pathogenesis, treatment and follow-up. Cancer Treat Rev. 2017;60:24-31.

49. Ruffini PA. The CXCL8-CXCR1/2 axis as a therapeutic target in breast cancer stemlike cells. Front Oncol. 2019;9:40.

50. Wei W, Lewis MT. Identifying and targeting tumor-initiating cells in the treatment of breast cancer. Endocr-Relat Cancer. 2015;22:R135-155.

51. Reverendo M, Mendes A, Arguello RJ, Gatti E, Pierre P. At the crossway of ERstress and proinflammatory responses. FEBS J. 2019;286:297-310.

52. Logue SE, McGrath EP, Cleary P, Greene S, Mnich K, Almanza A, et al. Inhibition of IRE1 RNase activity modulates the tumor cell secretome and enhances response to chemotherapy. Nat Commun. 2018;9:3267.

53. Guthrie LN, Abiraman K, Plyler ES, Sprenkle NT, Gibson SA, McFarland BC, et al. Attenuation of PKR-like ER kinase (PERK) signaling selectively controls endoplasmic reticulum stress-induced inflammation without compromising immunological responses. J Biol Chem. 2016;291:15830-40.

54. Pulido-Salgado M, Vidal-Taboada JM, Saura J. C/EBPbeta and C/EBPdelta transcription factors: Basic biology and roles in the CNS. Prog Neurobiol. 2015;132:1-33. 
55. Tam AB, Mercado EL, Hoffmann A, Niwa M. ER stress activates NF-kappaB by integrating functions of basal IKK activity, IRE1 and PERK. PLoS ONE. 2012;7:e45078.

56. Zhang K, Wang S, Malhotra J, Hassler JR, Back SH, Wang G, et al. The unfolded protein response transducer IRE1alpha prevents ER stress-induced hepatic steatosis. EMBO J. 2011;30:1357-75.

57. Grigoryan G, Reinke AW, Keating AE. Design of protein-interaction specificity gives selective bZIP-binding peptides. Nature. 2009;458:859-64.

58. Li C, Huang $Y$, Fan Q, Quan H, Dong $Y$, Nie M, et al. p97/NCP is highly expressed in the stem-like cells of breast cancer and controls cancer stemness partly through the unfolded protein response. Cell Death Dis. 2021;12:286.

59. Carro MS, Lim WK, Alvarez MJ, Bollo RJ, Zhao X, Snyder EY, et al. The transcriptional network for mesenchymal transformation of brain tumours. Nature. 2010;463:318-25.

60. Shacham T, Patel C, Lederkremer GZ. PERK pathway and neurodegenerative disease: to inhibit or to activate? Biomolecules. 2021;11:354.

61. Maas NL, Diehl JA. Molecular pathways: the PERKs and pitfalls of targeting the unfolded protein response in cancer. Clin Cancer Res. 2015;21:675-9.

62. Goldstein LJ, Perez RP, Yardley D, Han LK, Reuben JM, Gao H, et al. A window-ofopportunity trial of the CXCR1/2 inhibitor reparixin in operable HER-2-negative breast cancer. Breast Cancer Res. 2020;22:4

63. Schott AF, Goldstein $L$, Cristofanilli M, Ruffini PA, McCanna S, Reuben JM, et al. Phase lb pilot study to evaluate reparixin in combination with weekly paclitaxel in patients with HER-2-negative metastatic breast cancer. Clin Cancer Res. 2017;23:5358-65.

64. Brandolini L, Cristiano L, Fidoamore A, De Pizzol M, Di Giacomo E, Florio TM, et al. Targeting CXCR1 on breast cancer stem cells: signaling pathways and clinical application modelling. Oncotarget. 2015;6:43375-94.

65. Bachelerie F, Ben-Baruch A, Burkhardt AM, Combadiere C, Farber JM, Graham GJ, et al. International Union of Basic and Clinical Pharmacology. [corrected]. LXXXIX. Update on the extended family of chemokine receptors and introducing a new nomenclature for atypical chemokine receptors. Pharm Rev. 2014;66:1-79.

66. Fousek K, Horn LA, Palena C. Interleukin-8: a chemokine at the intersection of cancer plasticity, angiogenesis, and immune suppression. Pharm Ther. 2021;219:107692.

67. Madden EC, Gorman AM, Logue SE, Samali A. Tumour cell secretome in chemoresistance and tumour recurrence. Trends Cancer. 2020;6:489-505.

68. van Drogen F, Sangfelt O, Malyukova A, Matskova L, Yeh E, Means AR, et al. Ubiquitylation of cyclin $E$ requires the sequential function of SCF complexes containing distinct hCdc4 isoforms. Mol Cell. 2006;23:37-48.

69. Kolmykov S, Yevshin I, Kulyashov M, Sharipov R, Kondrakhin Y, Makeev VJ, et al. GTRD: an integrated view of transcription regulation. Nucleic Acids Res. 2021;49: D104-D111.

70. Wang J, Sarkar TR, Zhou M, Sharan S, Ritt DA, Veenstra TD, et al. CCAAT/enhancer binding protein delta (C/EBPdelta, CEBPD)-mediated nuclear import of FANCD2 by IPO4 augments cellular response to DNA damage. Proc Natl Acad Sci USA. 2010;107:16131-6.

\section{ACKNOWLEDGEMENTS}

We thank Linda Miller, Suzanne Specht, and student interns Robin Raley and Shayan Nazari for excellent assistance; Drs. Bao Tran and Jyoti Shetty (Leidos Biomedical Research, Inc., Frederick National Laboratory for Cancer Research) for mRNA-Seq data; Drs. Maggie Cam and Parthav Jailwala (CCR Collaborative Bioinformatics, CCBR) for bioinformatics support; Dr. Duncan Donohue (Data Management Services, Inc.) for expert statistics consultation; Allen Kane for preparation of the figures; Drs. Scott Durum, John Brognard and Chengkai Dai ( $\mathrm{NCl}$ ) and Naoto T. Ueno (MDACC) for kindly providing reagents.

\section{AUTHOR CONTRIBUTIONS}

NS, DKP and ES conceived the main concepts and designed the study; NS, DKP, $\mathrm{SS}$ and KB: developed methodology and experimental design and acquired data; $\mathrm{YH}$ and CY contributed mRNA-Seq data analysis; VNK contributed in silico ChIP analysis; NS, DKP, SS, KB and ES conducted analysis and interpretation of data; NS, DKP and ES wrote the manuscript; $\mathrm{KB}, \mathrm{YH}, \mathrm{CY}$ and SS contributed to the manuscript draft and revisions; all authors read and approved the final paper.

\section{FUNDING}

This research was supported by the Intramural Research Program of the $\mathrm{NIH}_{\text {, }}$ National Cancer Institute, and in part with Federal Funds under contract no. HHSN261200800001E. This work used the computational resources of the NIH HighPerformance Computing Biowulf Cluster. Open Access funding provided by the National Institutes of Health (NIH).

\section{COMPETING INTERESTS}

The authors declare no competing interests.

\section{ETHICS STATEMENT}

This study did not require ethical approval.

\section{ADDITIONAL INFORMATION}

Supplementary information The online version contains supplementary material available at https://doi.org/10.1038/s41419-021-04318-y.

Correspondence and requests for materials should be addressed to Namratha Sheshadri or Esta Sterneck.

Reprints and permission information is available at http://www.nature.com/ reprints

Publisher's note Springer Nature remains neutral with regard to jurisdictional claims in published maps and institutional affiliations.

(i) Open Access This article is licensed under a Creative Commons adaptation, distribution and reproduction in any medium or format, as long as you give appropriate credit to the original author(s) and the source, provide a link to the Creative Commons license, and indicate if changes were made. The images or other third party material in this article are included in the article's Creative Commons license, unless indicated otherwise in a credit line to the material. If material is not included in the article's Creative Commons license and your intended use is not permitted by statutory regulation or exceeds the permitted use, you will need to obtain permission directly from the copyright holder. To view a copy of this license, visit http://creativecommons. org/licenses/by/4.0/.

This is a U.S. government work and not under copyright protection in the U.S.; foreign copyright protection may apply 2021 